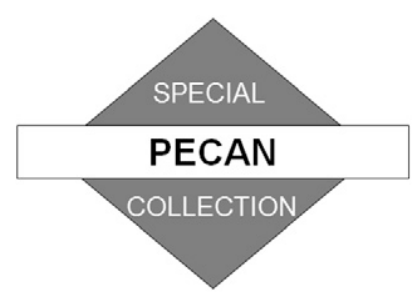

\title{
Spatiotemporal Evolution of the Microphysical and Thermodynamic Characteristics of the 20 June 2015 PECAN MCS
}

\author{
DANiEl M. Stechman, ${ }^{\mathrm{a}, \mathrm{b}, \mathrm{c}, \mathrm{f}}$ GReG M. MCFARquhar,${ }^{\mathrm{a}, \mathrm{d}}$ Robert M. Rauber,${ }^{\mathrm{c}}$ \\ MichaEl M. Bell, ${ }^{\mathrm{e}}$ BRIAN F. JEWEtT, ${ }^{\mathrm{c}}$ AND JONATHAN MARTINEZ ${ }^{\mathrm{e}}$

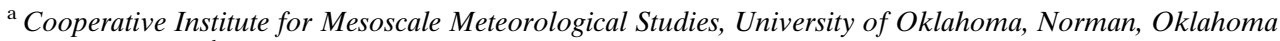 \\ ${ }^{\mathrm{b}}$ NOAA/OAR/National Severe Storms Laboratory, Norman, Oklahoma \\ ${ }^{\mathrm{c}}$ Department of Atmospheric Sciences, University of Illinois at Urbana-Champaign, Urbana, Illinois \\ ${ }^{\mathrm{d}}$ School of Meteorology, University of Oklahoma, Norman, Oklahoma \\ ${ }^{\mathrm{e}}$ Department of Atmospheric Science, Colorado State University, Fort Collins, Colorado
}

(Manuscript received 2 September 2019, in final form 18 December 2019)

\begin{abstract}
This study examines microphysical and thermodynamic characteristics of the 20 June 2015 mesoscale convective system (MCS) observed during the Plains Elevated Convection At Night (PECAN) experiment, specifically within the transition zone (TZ), enhanced stratiform rain region (ESR), anvil region, melting layer (ML), and the rear inflow jet (RIJ). Analyses are developed from airborne optical array probe data and multiple-Doppler wind and reflectivity syntheses using data from the airborne NOAA Tail Doppler Radar (TDR) and ground-based Weather Surveillance Radar-1988 Doppler (WSR-88D) radars. Seven spiral ascents/descents of the NOAA P-3 aircraft were executed within various regions of the 20 June MCS. Aggregation modified by sublimation was observed in each MCS region, regardless of whether the sampling was within the RIJ. Sustained sublimation and evaporation of precipitation in subsaturated layers led to a trend of downward moistening across the ESR spirals, with greater degrees of subsaturation maintained when in the vicinity of the descending RIJ. In all cases where melting was observed, the ML acted as a prominent thermodynamic boundary, with differing rates of change in temperature and relative humidity above and below the ML. Two spiral profiles coincident with the rear inflow notch provided unique observations within the TZ and were interpreted in the context of similar observations from the 29 June 2003 Bow Echo and Mesoscale Convective Vortex Experiment MCS. There, sublimation cooling and enhanced descent within the RIJ allowed ice particles to survive to temperatures as warm as $+6.8^{\circ} \mathrm{C}$ before completely sublimating/evaporating.
\end{abstract}

\section{Introduction}

The structure, dynamics, and evolution of midlatitude continental mesoscale convective systems (MCSs; all acronyms and abbreviations are listed in appendix B) are strongly influenced by microphysical processes. The important role of latent heating and cooling in driving the descent of the rear inflow jet (RIJ), production of stratiform precipitation, and the development of the

\footnotetext{
${ }^{\mathrm{f}}$ Current affiliations: Cooperative Institute for Mesoscale Meteorological Studies, University of Oklahoma, and NOAA/OAR/ National Severe Storms Laboratory, Norman, Oklahoma.
}

Corresponding author: Daniel M. Stechman, stechman@ou.edu wake low were first shown in early modeling studies of a squall line observed on 10-11 June 1985 during the Preliminary Regional Experiment for STORM-Central (PRE-STORM; Cunning 1986) (e.g., Zhang and Gao 1989; Gallus and Johnson 1995; Yang and Houze 1995; Gallus 1996; Braun and Houze 1997). Biggerstaff and Houze $(1991,1993)$ hypothesized that multiple factors contributed to the reflectivity minimum in the transition zone (TZ) between the convective line and the enhanced stratiform region (ESR) in this MCS, including mechanically driven gravity waves, microphysical cooling from melting and evaporation, and the absence of aggregation. Braun and Houze (1994) subsequently used thermodynamic and microphysical retrievals from the dual-Doppler kinematic analysis presented by 
Biggerstaff and Houze (1993) to conclude that the secondary maximum in radar reflectivity in the ESR was most strongly influenced by vapor deposition within mesoscale ascent in this region, coupled with enhanced aggregation above the melting layer (ML). Furthermore, they suggested that the suppression of ice crystal growth in the TZ is the dominant cause of the observed reflectivity minimum there. Meanwhile, idealized modeling studies (e.g., Pandya and Durran 1996; Pandya et al. 2000) have illustrated the importance of the latent heating profile in generating waves that drive storm-relative flow.

In situ cloud microphysical observations within and throughout MCSs are an important, though uncommon, tool for verifying and expanding upon the analyses of remote observations and modeling studies. An advecting spiral descent of the National Oceanic and Atmospheric Administration (NOAA) P-3 aircraft through the stratiform region of the 10-11 June 1985 PRE-STORM squall line enabled the collection of the first in situ microphysical observations within a midlatitude MCS. Willis and Heymsfield (1989) used these and coincident radar observations to show that the majority of melting and associated latent cooling occurs just above the radar bright band, and that the ice water content above the ML is several times greater than the liquid water content below.

The availability of in situ microphysical observations within MCSs was substantially enhanced during the 2003 Bow Echo and Mesoscale Convective Vortex Experiment (BAMEX; Davis et al. 2004). McFarquhar et al. (2007a, hereafter M07) presented in situ vertical profiles of the properties and concentrations of hydrometeors above, below, and within the ML in ESRs of MCSs collected during 16 spiral descents of the NOAA P-3 behind the convective line of 10 MCSs. Their results, together with column model studies (Grim et al. 2009, hereafter G09), suggested that a combination of aggregation and sublimation controlled the evolution of particle size distributions (PSDs) above the ML in the ESR, with the effects of sublimation decreasing as the environment evolved toward saturation with respect to ice. Their results showed that cooling from melting and evaporation in subsaturated air within and below the ML was the most important diabatic process in the ESR. Observations from a single spiral conducted on 29 June 2003 in the subsaturated rear inflow notch of a developing bow echo indicated that sublimation reduced ice particle aggregation and was the dominant diabatic process in that region. Subsequently, Smith et al. (2009, hereafter S09) used P-3 X-band Tail Doppler Radar (TDR) data to provide context to the microphysical profiles. They showed that sublimation reduced particle concentration and mass while cooling the environment above the ML in the early stages of MCS development, but became less important as the environment became ice saturated as the ESR matured.

Additional in situ measurements were made in the stratiform areas behind midlatitude and tropical MCSs during the 1999 Kwajalein Field Experiment (Yuter et al. 2005), the 2002 Cirrus Regional Study of Tropical Anvils and Cirrus Layers-Florida-Area Cirrus Experiment (Jensen et al. 2004), and the 2011 Midlatitude Continental Convective Clouds Experiment (MC3E; Jensen et al. 2016). Heymsfield et al. (2015) used data from all three experiments to show that the maximum particle size increased while descending through the ML, regardless of whether the environment was saturated or highly subsaturated. They further showed that little melting occurred in highly subsaturated conditions, with all particles experiencing sublimation. Marinescu et al. (2016) used in situ data from MC3E to constrain and verify their model simulation, which showed that evaporative cooling dominates below cloud base in the convective region of MCSs, cooling from evaporation, sublimation, and melting are important and altitude dependent in the ESR, and that sublimation is the dominant cooling process in the anvil region. While evaporative and sublimative cooling rates in the convective line and ESR decreased as the MCS matured and weakened, they found minimal changes in latent cooling with time within the anvil region.

The Plains Elevated Convection At Night (PECAN; Geerts et al. 2017) project took place over the Great Plains during June and July 2015. PECAN data are being used to improve the understanding of processes controlling initiation, organization, and maintenance of nocturnal MCSs. Instruments on the P-3 acquired detailed in situ microphysical and thermodynamic observations during spiral ascents/descents across six MCS missions. The MCS observed on 20 June 2015 most closely corresponded to the classic leading-line/trailing stratiform archetype described by Houze et al. (1989), allowing for observations to be considered within a common and recognizable conceptual framework (Fig. 1) and hence providing information about the dominant processes occurring within each region at different stages of evolution. During this mission, the P-3 executed seven spirals in different regions and stages of evolution of the MCS. Four spirals transected the RIJ. In situ microphysical and thermodynamic observations obtained within these spirals, coupled with P-3 and ground-based Weather 


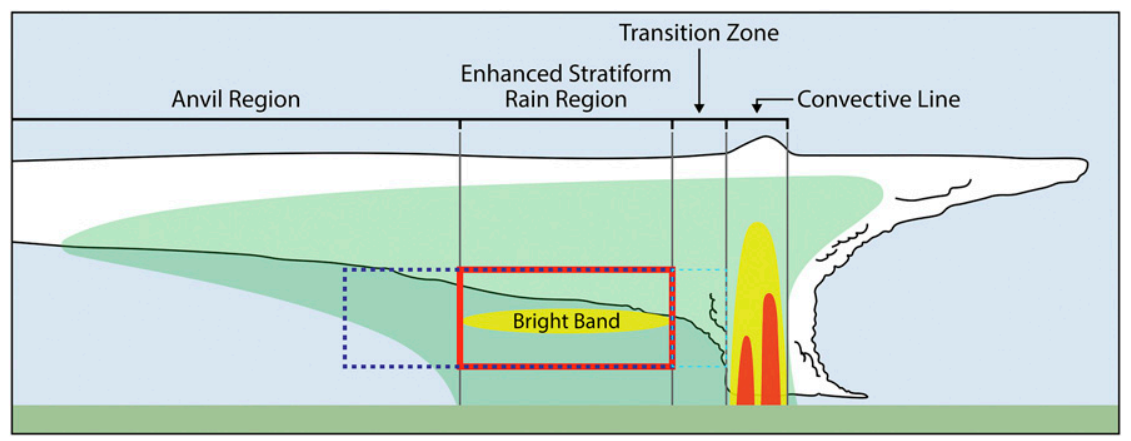

FIG. 1. Schematic cross section of an MCS with a leading convective line and trailing stratiform region, adapted from Houze et al. (1989). Green shading represents regions where precipitation echo is present on radar, while yellow and red shading represent regions of higher radar reflectivity. The general location of the radar bright band is also indicated. The four primary MCS regions: the convective line, transition zone (TZ), enhanced stratiform region (ESR), and anvil region are shown. The relative location of observations from $20 \mathrm{Jun}$ 2015 in the vicinity of the RIJ within the ESR are bounded by the red box (corresponds to Fig. 22a), and those within the TZ are bounded by the dashed light blue box (corresponds to Fig. 22b). Observations removed from the RIJ are bounded by the dashed dark blue box (corresponds to Fig. 22c).

Surveillance Radar-1988 Doppler (WSR-88D) radar observations, are used herein to analyze the thermodynamic and microphysical characteristics of the 20 June 2015 MCS. Multiple-Doppler syntheses are used to interpret microphysical observations in the context of storm structure, especially with regard to their location relative to the RIJ. These analyses are compared to observations from a single spiral profile collected within the rear inflow notch of the 29 June 2003 BAMEX MCS, the only other data within this region of an MCS, to better understand how the evaporation, melting, and sublimation vary in time and with respect to MCS region and the RIJ.

\section{Data sources and methods}

This study examines the microphysical and thermodynamic characteristics of the 20 June 2015 MCS sampled over South Dakota during PECAN Unofficial Field Operation 4. The location of this MCS was too far north of the PECAN operational domain to be targeted by any of the ground-based assets available during the project, limiting observations of this system to those collected aboard the NOAA P-3. The P-3 executed seven spiral ascents/descents (henceforth, spiral profiles) in the trailing stratiform region of the MCS, four of which transected the RIJ. No attempt was made to perform quasi-Lagrangian spiral descents that are designed to track the fall of particles (Lo and Passarelli 1982; M07). Instead, the $\mathrm{P}-3$ ascended or descended at approximately $5 \mathrm{~m} \mathrm{~s}^{-1}$, allowing time for more spirals to be executed, and avoiding aircraft charging near and within the ML. The spirals provided temperature-dependent profiles of atmospheric state and cloud microphysical parameters. When considered in the context of system structure and stage of growth, these provide insight into microphysical and thermodynamic processes, even though the action of those processes on specific particle populations could not be tracked.

\section{a. Thermodynamic measurements}

The P-3 was equipped with a Rosemount 102 total temperature sensor and two chilled mirror hygrometers (Buck Research 1011C and Edgetech Instruments 137) for measuring dewpoint temperature. Following M07, the Zipser et al. (1981) sensor wetting correction was applied to the flight-level temperature and dewpoint measurements, the corrected temperature values hereafter referred to as T. Zipser et al. (1981)

TABLE 1. Characteristics of the NOAA P-3 TDR, valid for the entirety of the 2015 PECAN campaign. PRF is the pulse repetition frequency, $R_{\max }$ is the maximum unambiguous range of the radar, and $V_{\max }$ is the Nyquist velocity.

\begin{tabular}{lc}
\hline \hline Fore/aft antenna tilt $\left(^{\circ}\right)$ & $20.0 /-20.0$ \\
Wavelength $(\mathrm{cm})$ & 3.22 \\
Frequency $(\mathrm{GHz})$ & 9.31 \\
Beamwidth $\left(^{\circ}\right)$ & 1.98 \\
Along-beam resolution $(\mathrm{m})$ & 75 \\
Along-track resolution $(\mathrm{m})$ & 750 \\
Low/high PRF $(\mathrm{Hz})$ & $1575 / 2100$ \\
$R_{\max }\left(\mathrm{km}^{-1}\right)$ & 71.38 \\
$V_{\max }\left(\mathrm{m} \mathrm{s}^{-1}\right)$ & 50.72 \\
\hline
\end{tabular}




\section{June 2015 - Spiral 5 - 06:13 UTC}
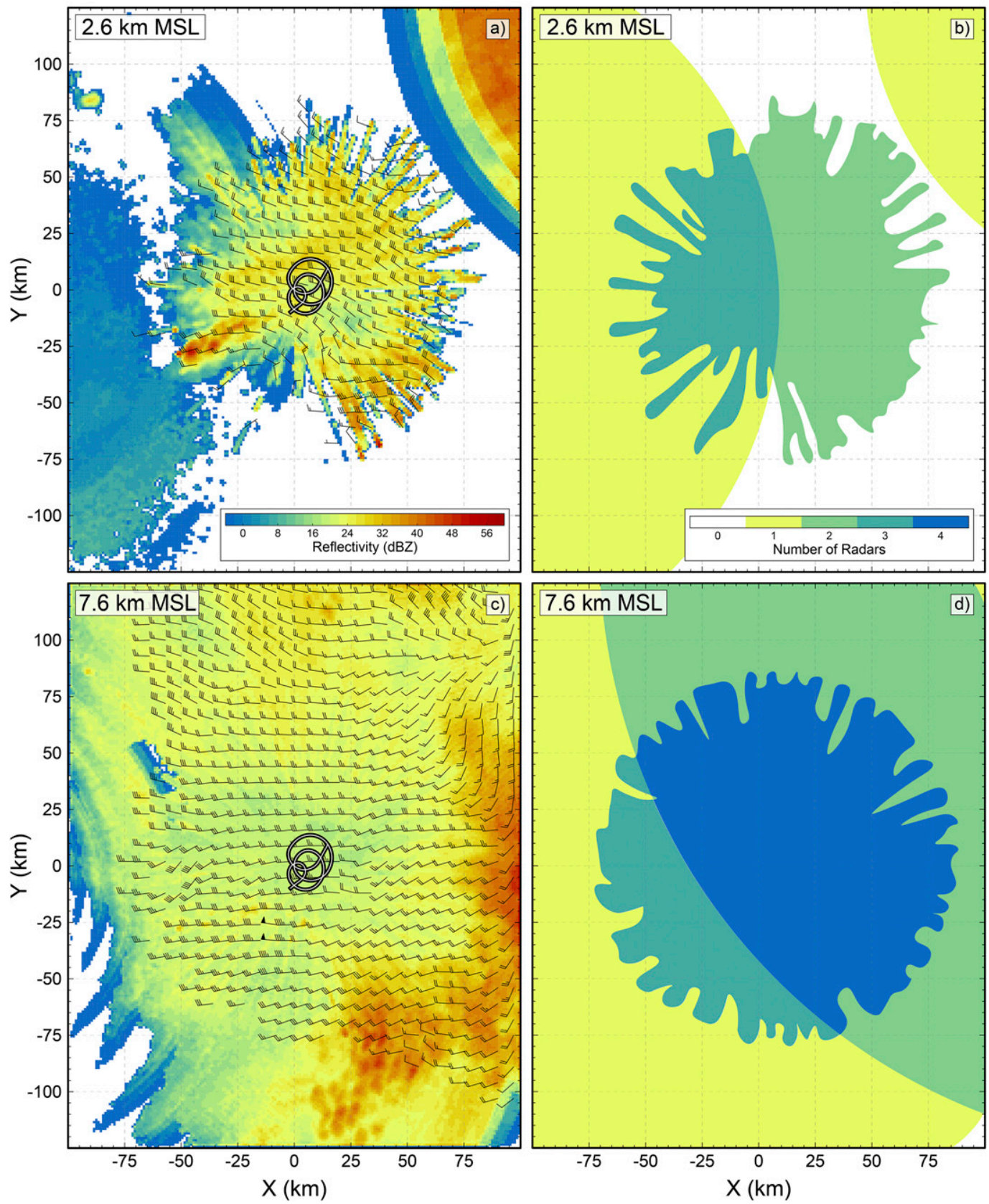

FIG. 2. Example of synthesized radar reflectivity and ground-relative winds at (a) 2.6 and (c) $7.6 \mathrm{~km}$ MSL from the Spiral 5 SAMURAI analysis, valid at 0613 UTC 20 Jun 2015. Wind barb flags, long barbs, and short barbs indicate values of 50,10 , and $5 \mathrm{~m} \mathrm{~s}^{-1}$, respectively. The black and white lines indicate the flight track of the P-3 for the period of time included in the analyses. (b),(d) Correspond to the same analyses and levels in (a) and (c), respectively, but show the number of radars contributing to the analyses throughout the domain.

estimated the maximum error in the corrected $T$ and dewpoint to be approximately $1.5^{\circ} \mathrm{C}$. Using $T$ and the corrected dewpoint measurement, flight-level relative humidity with respect to water and ice was computed using the sixth-order polynomial and associated coefficients for water and ice provided by Lowe and Ficke (1974), who note that the estimated errors in both vapor pressure and saturation vapor 


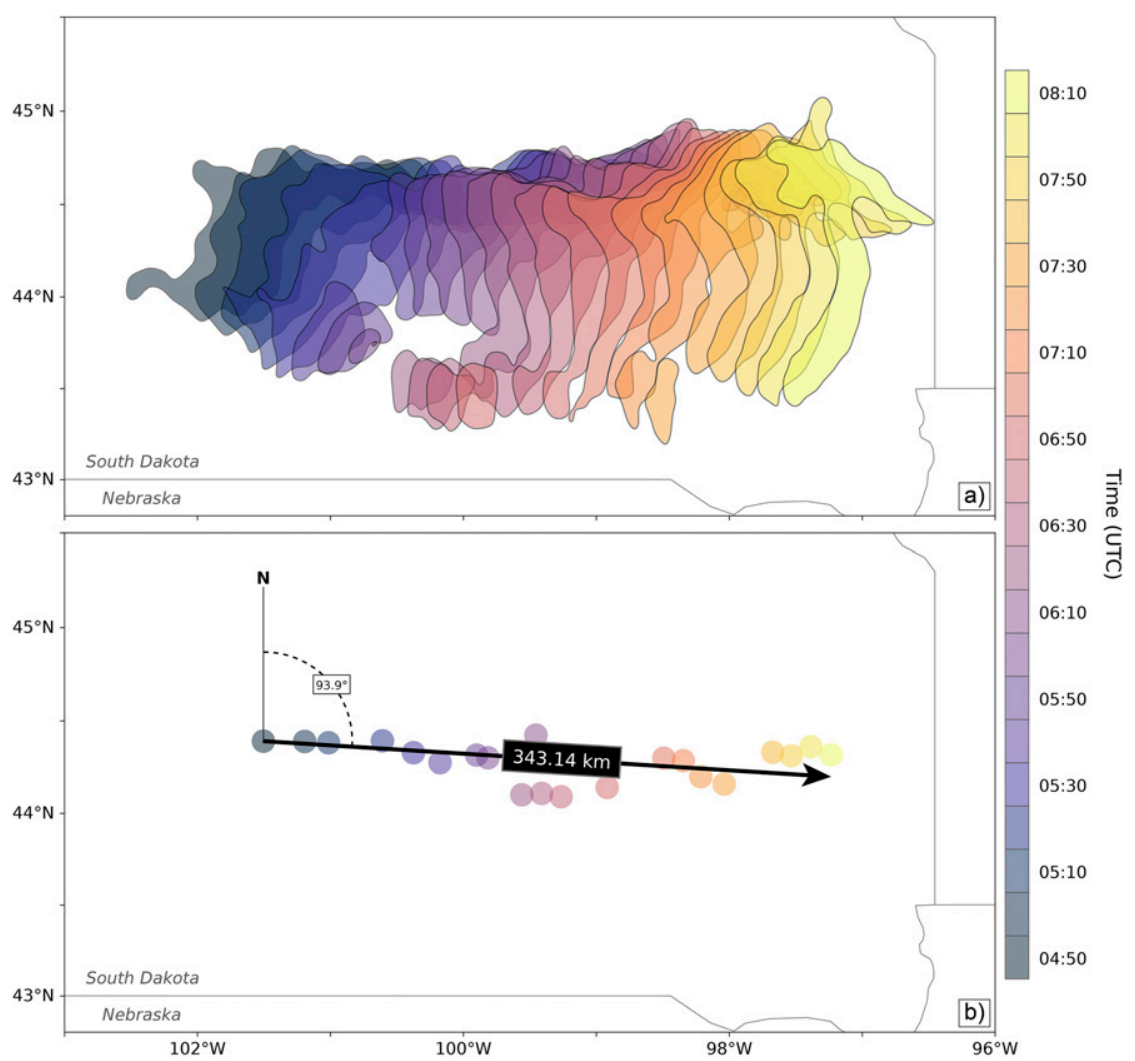

FIG. 3. (a) Multi-Radar Multi-Sensor SHSR $37 \mathrm{dBZ}$ reflectivity isodops drawn at $10 \mathrm{~min}$ increments spanning the period of P-3 observations of the 20 Jun 2015 MCS. (b) Geometric centroids for each of the 10-min $37 \mathrm{dBZ}$ isodops shown in (a), complete with a subjective bestfit line used in the determination of the average storm motion vector.

pressure are less than $1 \%$. Unless otherwise stated, relative humidity $(\mathrm{RH})$ was calculated with respect to liquid water for $T>0^{\circ} \mathrm{C}$, and with respect to ice for $T \leq 0^{\circ} \mathrm{C}$.

\section{b. Microphysical measurements and processing}

A Droplet Measurement Technologies Cloud Imaging Probe (CIP) and a Precipitation Imaging Probe (PIP) were installed on the P-3 to measure cloud and precipitation particle properties. The CIP and PIP are 64 element optical array probes (OAPs) with sizing elements of 25- and $100-\mu \mathrm{m}$ resolution, respectively, nominally allowing for the detection of particles with maximum dimension $(D$; diameter of smallest circle enclosing each particle $\mathrm{Wu}$ and McFarquhar 2016) ranging from $25 \mu \mathrm{m}$ to $6.2 \mathrm{~mm}$. The PIP malfunctioned during PECAN, and after a thorough analysis and comparison of observations with those from the CIP, the PIP data were determined to be unusable. Thus, the largest resolvable $D$ was approximately $2 \mathrm{~mm}$ when reconstructing particles whose edges were beyond, but centers within, the CIP sample area. To better characterize PSDs for particle sizes normally observed by the PIP, estimates of size-resolved and bulk microphysical parameters for particles with $D$ up to $12 \mathrm{~mm}$ were obtained by forcing mass closure between the CIP and the bulk total water content (TWC) measured by the Science Engineering Associates Inc. (SEA) multielement water content system (WCM-2000; Strapp et al. 2008). This procedure is described in detail in appendix A.

The University of Illinois/Oklahoma OAP Processing Software (McFarquhar et al. 2018; see also McFarquhar et al. 2017) was used to decompress the raw CIP data, perform quality control, and determine particle-byparticle characteristics, 1- and 10-s averaged PSDs, and bulk parameters. The area ratio $(\mathcal{A}$; McFarquhar and Heymsfield 1996) of each particle was defined as the projected area of a particle divided by the area of a circle with diameter $D$. Particles with $\mathcal{A}<0.2$ were rejected as artifacts, and particles with $D<125 \mu \mathrm{m}$ were discarded due to the small and highly uncertain CIP depth of field (Baumgardner and Korolev 1997) and because of the possible existence of undetected shattered artifacts (e.g., Korolev and Isaac 2005; McFarquhar et al. 2007b, 2011; 


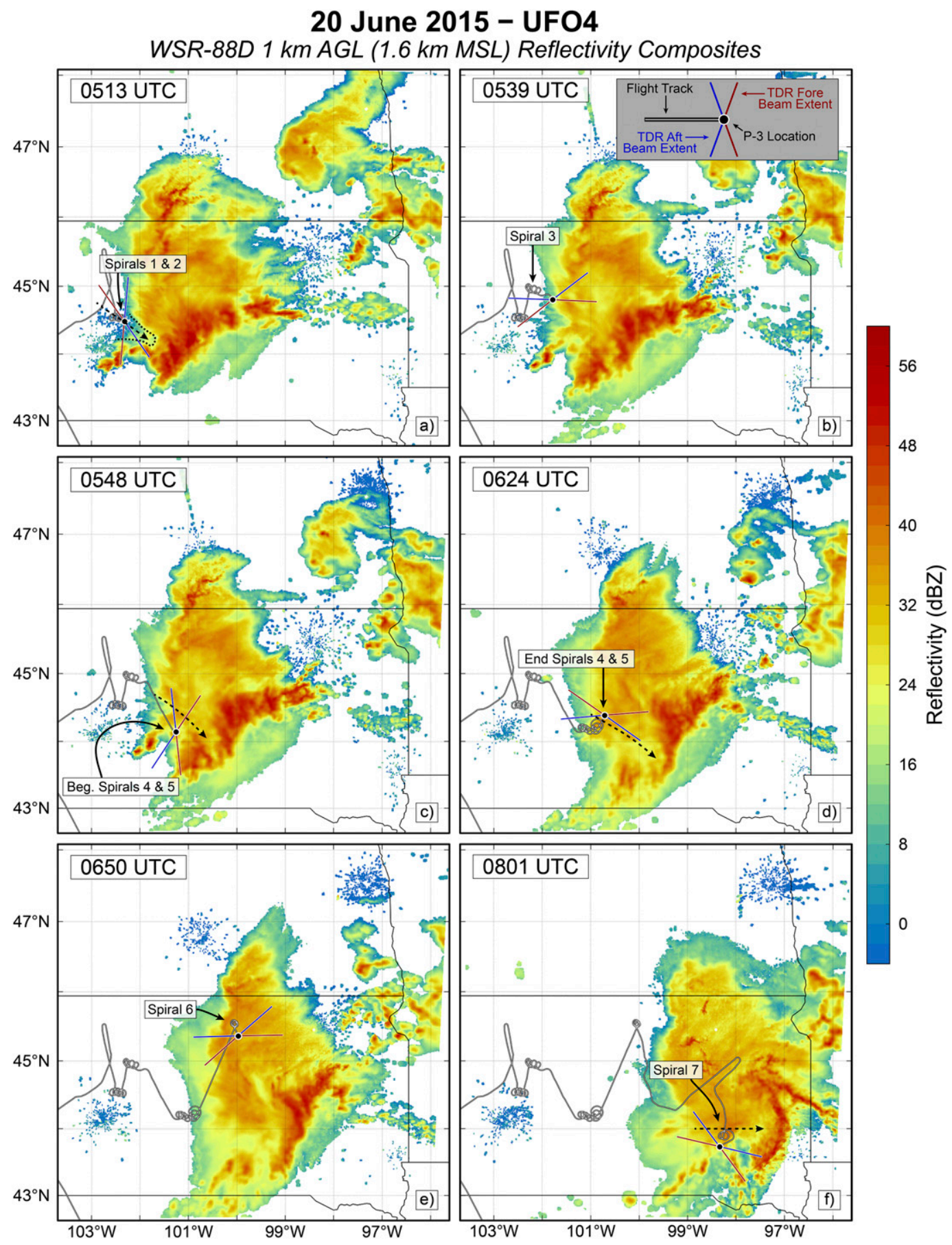

FIG. 4. Radar reflectivity composites at $1 \mathrm{~km}$ AGL (1.6 km MSL) composited from WSR-88D observations of the 20 Jun 2015 MCS between 0513 and 0801 UTC, with the flight track (gray line) and current location of the P-3 (black dot, white edge) shown along with the location and maximum range of the fore and aft beams of the TDR (red and blue lines, respectively). The dotted black outline in (a) denotes the location of the rear inflow notch at that time, and the dashed black arrow in (a), (c), (d), and (f) refer to the approximate location and direction of the main RIJ axis.

Jackson et al. 2014). Antishattering probe tips (Korolev et al. 2011) were not installed on the CIP during PECAN. To minimize the inclusion of shattered artifacts while retaining as many natural particles as possible, artifacts were removed based on the distribution of particle interarrival times (the time interval between the arrival of each particle in the sample volume) following Field et al. $(2003,2006)$. The interarrival time threshold for 
TABLE 2. Starting and ending altitudes (MSL), minimum and maximum observed $T$ and RH, $d T / d z$, and $T$ at the top and bottom of the ML [if observed; dashes (-) indicate either the ML was not sampled or that the available data were inconclusive] within each 20 Jun 2015 PECAN spiral and the first 29 Jun 2003 BAMEX spiral. The location of each spiral relative to key MCS regions and features is also provided.

\begin{tabular}{ccccccccccc}
\hline \hline Spiral & $\begin{array}{c}\text { MCS } \\
\text { region }\end{array}$ & $\begin{array}{c}\text { Beginning } \\
\text { altitude }(\mathrm{km})\end{array}$ & $\begin{array}{c}\text { Ending } \\
\text { altitude }(\mathrm{km})\end{array}$ & $\begin{array}{c}\text { Min } \\
T\left({ }^{\circ} \mathrm{C}\right)\end{array}$ & $\begin{array}{c}\text { Max } \\
T\left({ }^{\circ} \mathrm{C}\right)\end{array}$ & $\begin{array}{c}d T / d z \\
\left({ }^{\circ} \mathrm{C} \mathrm{km}{ }^{-1}\right)\end{array}$ & $\begin{array}{c}\text { Min } \\
\text { RH }(\%)\end{array}$ & $\begin{array}{c}\text { Max } \\
\mathrm{RH}(\%)\end{array}$ & $\begin{array}{c}\text { ML top } \\
T\left({ }^{\circ} \mathrm{C}\right)\end{array}$ & $\begin{array}{c}\text { ML bottom } \\
T\left({ }^{\circ} \mathrm{C}\right)\end{array}$ \\
\hline S1 & TZ/RIJ & 5.94 & 7.33 & -17.6 & -9.3 & -5.84 & 98.5 & 118.8 & - & - \\
S2 & TZ/RIJ & 7.33 & 2.88 & -17.6 & 15.4 & -7.41 & 28.0 & 118.7 & 0.0 & 6.8 \\
S3 & Anvil & 2.86 & 6.67 & -15.9 & 12.0 & -7.35 & 44.5 & 116.8 & - & - \\
S4 & ESR/RIJ & 6.67 & 2.60 & -13.0 & 16.1 & -6.61 & 37.9 & 113.6 & 0.2 & 5.9 \\
S5 & ESR/RIJ & 2.54 & 6.68 & -13.6 & 14.7 & -6.47 & 46.6 & 114.2 & 0.2 & 5.8 \\
S6 & ESR & 6.64 & 2.54 & -13.4 & 9.6 & -5.17 & 86.5 & 114.0 & 2.3 & 4.6 \\
S7 & ESR/RIJ & 2.56 & 6.66 & -13.2 & 12.2 & -6.00 & 66.9 & 113.8 & 0.0 & 4.7 \\
B1 & TZ/RIJ & 2.76 & 5.21 & -9.33 & 9.16 & -7.16 & 51.8 & 105.8 & 2.5 & 6.8 \\
\hline
\end{tabular}

distinguishing between artifacts and natural particles was determined on a spiral-by-spiral basis, where the average threshold across all PECAN spirals was $3.5 \times$ $10^{-5} \mathrm{~s}$. Particles with an interarrival time below the threshold were removed, along with the particle immediately preceding if $D<500 \mu \mathrm{m}$.

After removing artifacts, each particle was assigned one of nine habit classifications following Holroyd (1987). The mass of an individual particle was then determined as $m=a D^{b}$ using the habit-dependent coefficients $a$ and $b$ summarized by Jackson et al. (2012, 2014), who demonstrated this method provided mass estimates closer to measurements of bulk mass when particle habit is known compared to other available methods. Some of these mass-diameter $(m-D)$ relationships were formulated using a different definition of particle dimension than $D$ (e.g., the Brown and Francis (1995) $m-D$ relationship which used mean particle dimension), and were thus adjusted accordingly following Hogan et al. (2012).

To characterize the vertical variability of hydrometeor shape and size as a function of $T$ for each spiral, particle images representative of the habits present were manually selected for $1^{\circ} \mathrm{C}$ bins. Every effort was made to
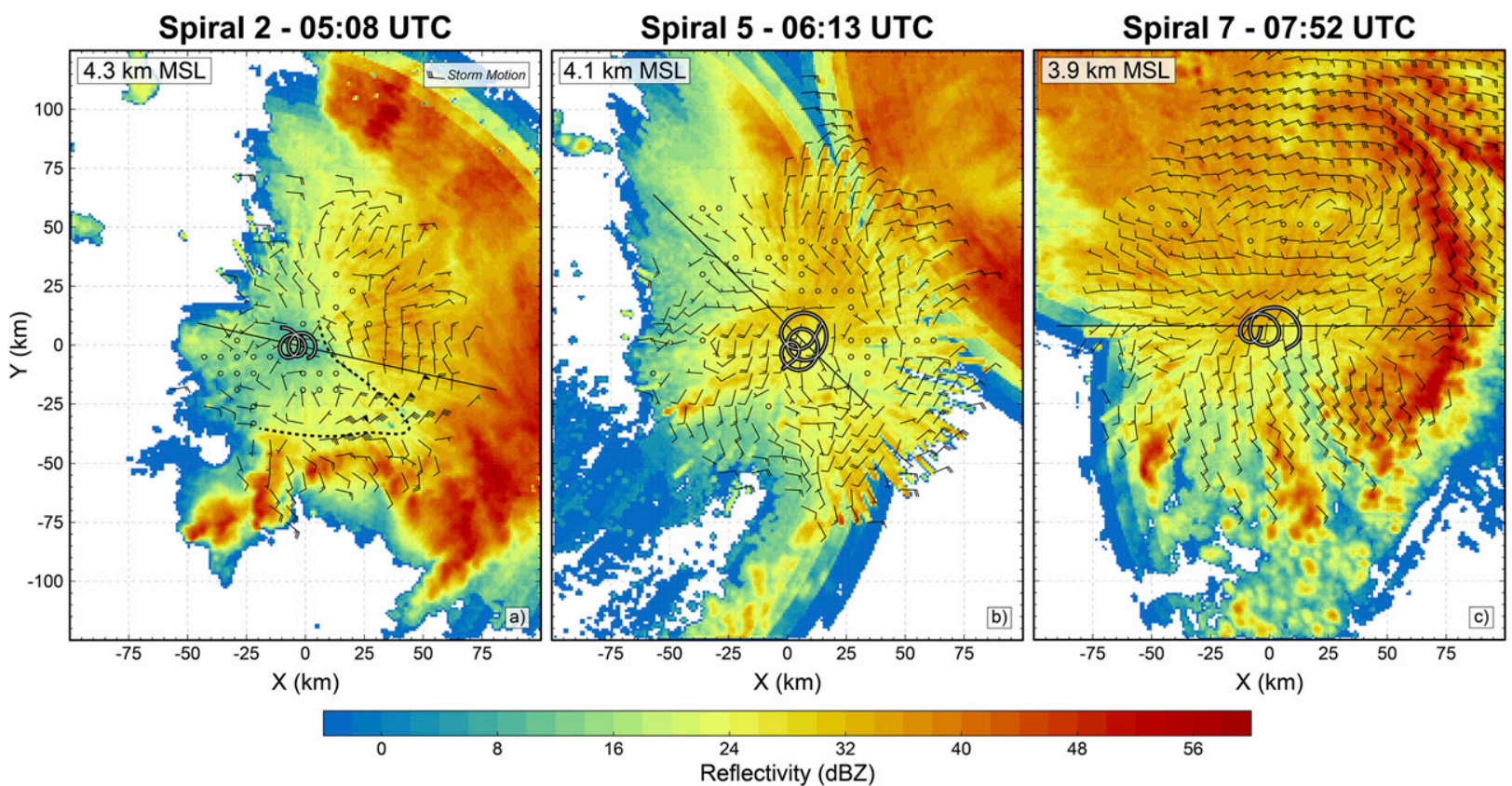

FIG. 5. Radar reflectivity and storm-relative winds determined by the S2, S5, and S7 SAMURAI analyses at $3.5 \mathrm{~km}$ AGL (reported in MSL) in (a), (b), and (c), respectively. Wind barb flags represent $50 \mathrm{~m} \mathrm{~s}^{-1}$, long barbs are equal to $10 \mathrm{~m} \mathrm{~s}^{-1}$, and short barbs represent $5 \mathrm{~m} \mathrm{~s}^{-1}$. The storm motion vector is provided in the upper-right corner of (a). TDR data collected along the P-3 flight tracks shown (white lines with black outline) were used in each SAMURAI analysis. The solid black line in each panel designates the location of the cross sections in Figs. 6, 15, and 19. The dashed black line in (a) denotes the approximate location of the rear inflow notch referred to in the text. 


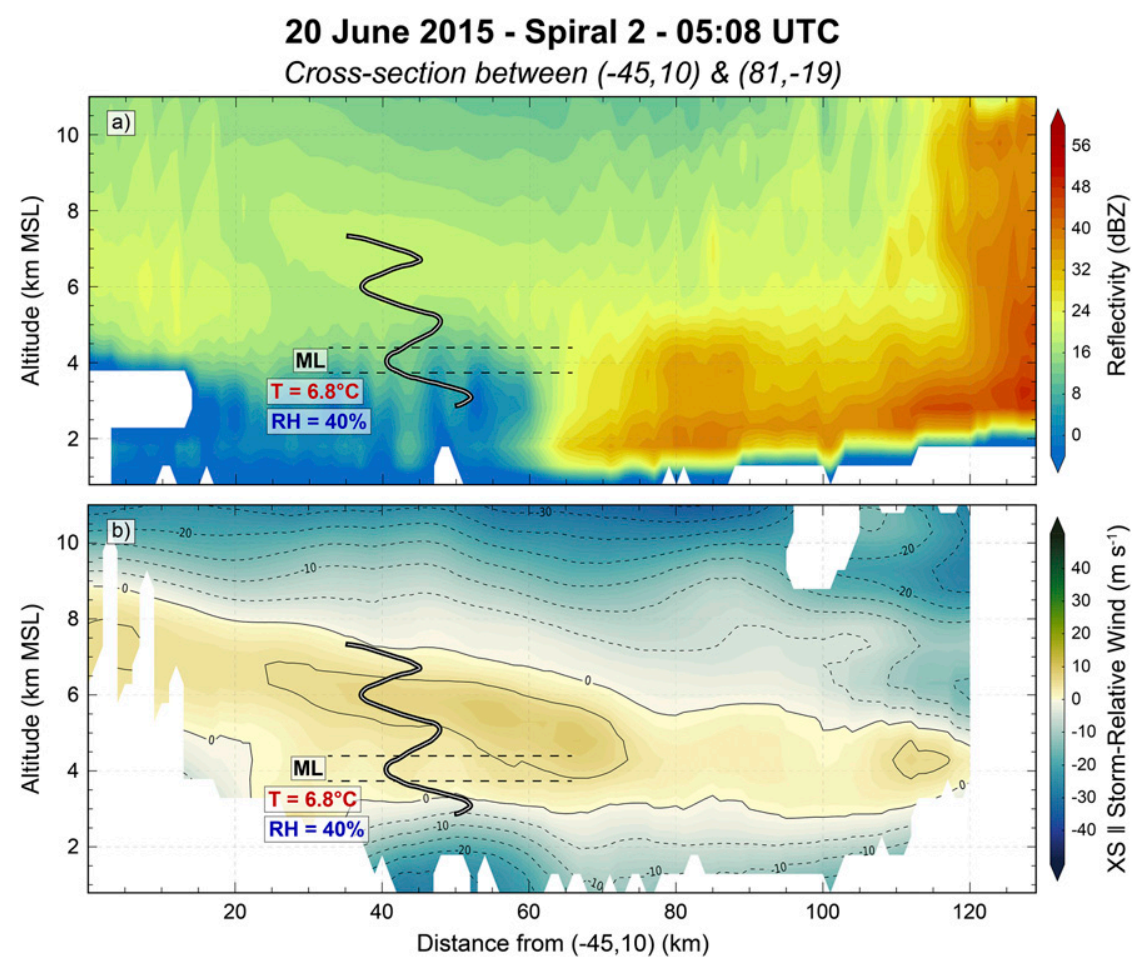

FIG. 6. Vertical cross section through S2 given by the solid black line in Fig. 5a, showing (a) reflectivity and (b) cross-section-parallel storm-relative winds, where solid black contours designate positive values (left to right) every $5 \mathrm{~m} \mathrm{~s}^{-1}$ and dashed black contours are negative values (right to left) also every $5 \mathrm{~m} \mathrm{~s}^{-1}$ (contour colors change to white at $\pm 40 \mathrm{~m} \mathrm{~s}^{-1}$ for readability). Each panel shows the two-dimensional P-3 flight track as viewed from the plane of the cross section (white line, black outline), the location of the top and bottom of the ML in the vicinity of the spiral (bold dashed black lines), and the $T$ and $\mathrm{RH}$ values observed at the bottom boundary of the ML.

reflect the true proportions of shapes and sizes when constructing these plots; however, they should not be interpreted quantitatively in the context of contributions of different particle habits to particle number distribution $[N(D)]$ or mass distribution function $[M(D)]$. Averages of particle $\mathcal{A}$ were also determined to give a quantitative measure of how particle shape varied with temperature and between spirals.

The temperatures of the top and bottom of the ML, if present in the sampled region, were determined by inspection of all particle images acquired. The top of the ML was defined where melting was first observed, as characterized by the presence of ice crystals whose edges were rounder than the often sharp, well-defined edges of crystals at subfreezing temperatures. The bottom of the ML was defined where all observed particles were spheroids. If no time periods with exclusively spheroidal particles were observed, the ML bottom was indeterminate, and recorded as the highest temperature where the observed transition to liquid water was not yet complete. The boundaries of the ML were used in the calculation of TWC. The mass of particles above the ML within the observed size range ( $D \leq 2 \mathrm{~mm}$ ) was determined using the habit-dependent mass coefficients described previously, while the mass of larger particles was determined using the modified Brown and Francis (1995) $m-D$ relationship. Particles observed below the bottom of the ML were assumed to have a density of $1 \mathrm{~g} \mathrm{~cm}^{-3}$, and a spherical volume weighted by the spiral-averaged, $T>0^{\circ} \mathrm{C}, \mathcal{A}$ to account for the prolate nature of the drops. The determination of particle mass in mixed-phase conditions was indeterminate, since no $m-D$ relationships currently exist for mixed-phase particles.

To characterize overall changes in the sampled particle populations and their environments, the average rates of change in thermodynamic and bulk microphysical quantities with respect to increasing $T$ were calculated over vertical layers using a linear least squares fit to those data. Following M07, the fractional rates of change of total number concentration $\left(N_{t}\right)$ and TWC were derived from fits to $\log _{10} N_{t}$ and $\log _{10}$ TWC, 
allowing for direct comparison of changes in these quantities irrespective of their relative magnitudes.

Spiral data from the notch region of the 20 June 2015 PECAN MCS are directly compared to that collected previously in the 29 June 2003 BAMEX MCS. Data collected within the BAMEX MCS, which used the Particle Measurement Systems two-dimensional cloud (2DC) and precipitation (2DP) probes, were reprocessed following similar procedures as outlined above to take advantage of improvements in the processing codes and to allow for consistent comparisons with the PECAN data. The most notable difference from previously published analyses was the identification and removal of shattered artifacts, which were not accounted for in the original studies (M07; S09; G09), and the use of a common set of habit-dependent $m-D$ relationships. In this study, 2DC data for $D<1 \mathrm{~mm}$ were combined with 2DP data for $D \geq 1 \mathrm{~mm}$ for BAMEX, yielding combined PSDs spanning $150 \mu \mathrm{m}-6.8 \mathrm{~mm}$.

\section{c. Radar observations, processing, and synthesis}

Radar data from the NOAA P-3 TDR and several NWS WSR-88D 10-cm wavelength S-band operational radars were synthesized using the Spline Analysis at Mesoscale Utilizing Aircraft and Radar Instrumentation (SAMURAI; Bell et al. 2012) radar wind synthesis software. The Rapid City (KUDX), Aberdeen (KABR), and Sioux Falls, South Dakota (KFSD), radars were the only WSR-88Ds with coverage within range of the 20 June MCS over the duration of the P-3 mission, and were used to constrain the SAMURAI analyses and extend the radar analysis domain beyond that of the TDR. All WSR-88D observations were edited using the National Center for Atmospheric Research Solo II package (Oye et al. 1995) to remove nonmeteorological echoes and unfold radial velocities.

At the time of PECAN, the TDR consisted of a single 3.22-cm wavelength X-band Doppler radar which used the fore/aft scanning technique (Jorgensen et al. 1996) whereby the radar alternated between two separate conically scanning antennas, pointing $20^{\circ}$ fore and aft of the P-3, every full $360^{\circ}$ sweep. Key characteristics of the TDR are provided in Table 1 (Jorgensen et al. 1996; D. P. Jorgensen and C. Ziegler, personal communication, 2017). Though observations from the TDR are of higher temporal and spatial resolution than those from the WSR-88Ds, the smaller wavelength of the TDR increased attenuation, limiting the ability of the TDR to fully resolve the ESR and convective line within its maximum unambiguous range.

The TDR data were corrected to account for the movement of the P-3 platform by applying navigation corrections (Cai et al. 2018) using Solo II. A hybrid of

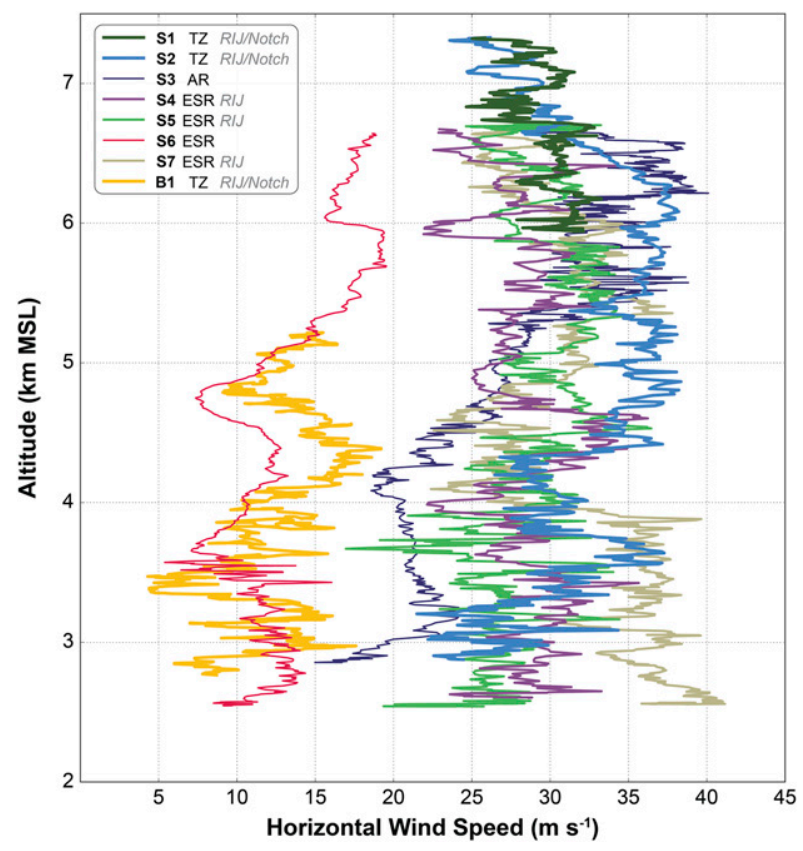

FIG. 7. Horizontal ground-relative wind speed $\left(\mathrm{m} \mathrm{s}^{-1}\right)$ observed aboard the P-3 as a function of altitude (km) MSL for all 20 Jun PECAN spirals along with the first 29 Jun BAMEX spiral. The MCS region where each spiral occurred and an indication of whether the given spiral occurred in the vicinity of the RIJ or rear inflow notch of the MCS are provided in the legend.

the quality control levels outlined in Bell et al. (2013) were applied to the TDR data to remove noise, surface returns, and other nonmeteorological echoes. The TDR data for 20 June were not affected by velocity folding because a dual-pulse repetition frequency (PRF) technique (Jorgensen et al. 2000) was used during PECAN. However, this technique can produce unfolding errors by the radar signal processor in regions of high wind shear or turbulence, which was common within the PECAN MCS environments. Improper dual-PRF unfolding errors in the TDR data were corrected using an algorithm provided by Alford et al. (2018), which uses a similar, but more robust identification and correction method than that of Joe and May (2003). The final step in the TDR quality control involved manually reviewing and editing each radar volume to remove any remaining spurious echoes.

The SAMURAI software minimizes a three-dimensional variational cost function, using cubic B-spline finite elements, to provide a maximum likelihood estimate of radar reflectivity and three-dimensional winds from a given set of observations. Bell et al. (2018) and the present study represent the first uses of SAMURAI for the analysis of MCSs. Three SAMURAI analyses were conducted for this study, with the domain for each defined as $200 \mathrm{~km} \times 250 \mathrm{~km} \times 16 \mathrm{~km}$ in $x, y$, and $z$, 


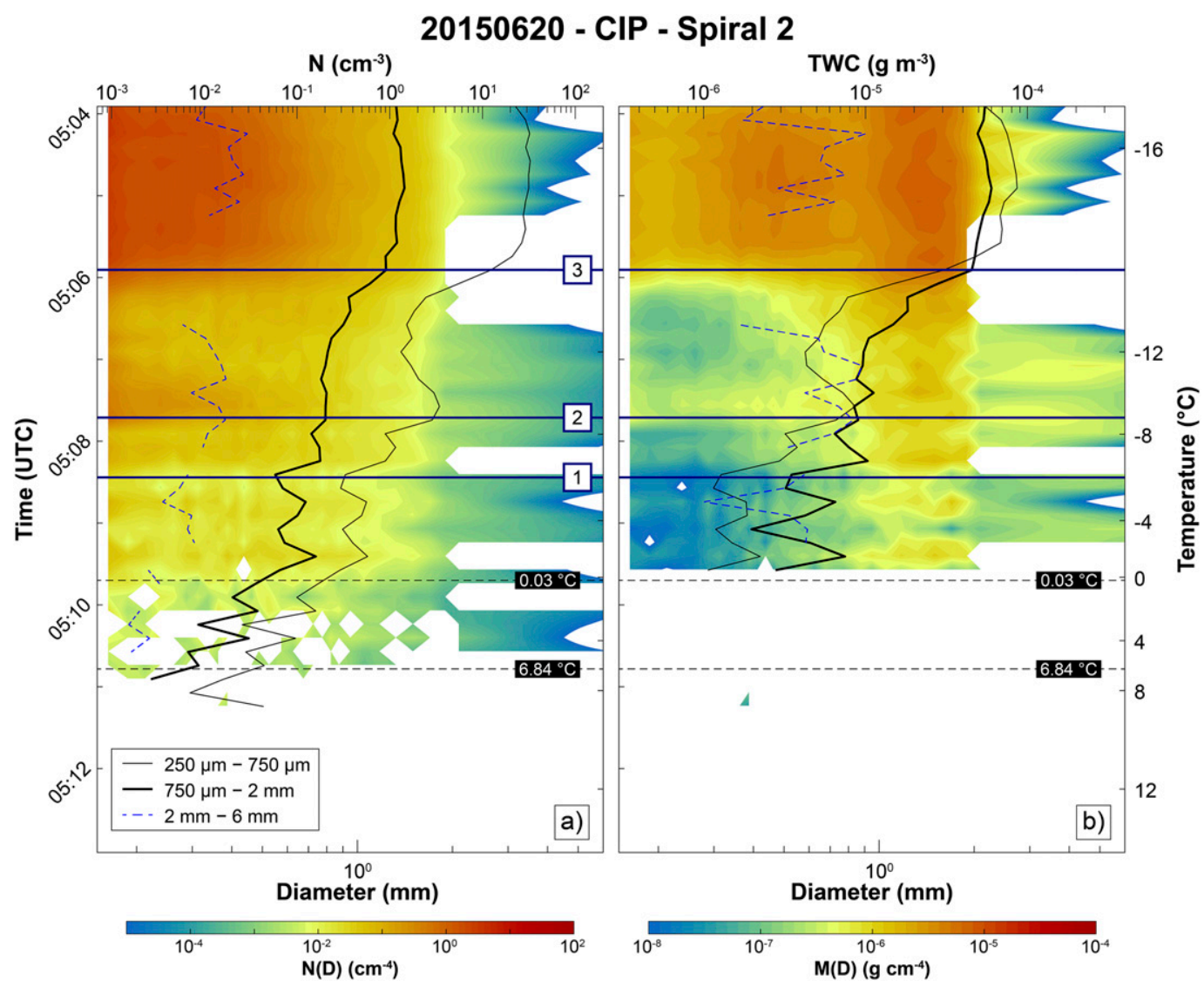

FIG. 8. Extended CIP observations of (a) $N(D)$ and (b) $M(D)$ within $\mathrm{S} 2$ as functions of both time (UTC) and $T$ $\left({ }^{\circ} \mathrm{C}\right)$. The thin black trace in (a) and (b) represents the number concentration, $N\left(\mathrm{~cm}^{-3}\right)$, and TWC $\left(\mathrm{g} \mathrm{m}^{-3}\right)$ for $250 \leq D \leq 750 \mu \mathrm{m}$, respectively. The bold black and dashed blue traces represent the same quantities but for $750 \mu \mathrm{m}<D \leq 2 \mathrm{~mm}$ and $2<D \leq 6 \mathrm{~mm}$, respectively. The horizontal dashed black lines indicate the boundaries of the ML, with the value of $T$ provided for each. Dark blue horizontal lines refer to key periods discussed further in the text. 1) top of the subsaturated layer, 2) first instance of subsaturation encountered in the spiral descent, and 3) level where the P-3 began to descend through the RIJ flow maxima.

respectively, with horizontal grid spacing of $1 \mathrm{~km}$ and vertical grid spacing of $0.5 \mathrm{~km}$, centered at the midpoint (in time) of the P-3 within the spiral profile of each analysis. These spatial resolutions are of the same order as the resolution of the input radar observations. Three-dimensional mass-continuity was applied, assuming vertical velocities were $0 \mathrm{~m} \mathrm{~s}^{-1}$ at the top and bottom of the domain. A $6 \Delta x$ and $2 \Delta z$ Gaussian filter was used to suppress higher-frequency fluctuations in the data (Purser et al. 2003), limiting the impact of noise within the data. This filter also filled gaps in the observations between elevation cuts in the horizontal due to beam spreading for the WSR-88D observations, and due to the irregular beam spacing in all dimensions inherent in the atypical Doppler geometry of the TDR data collected at the outer edges of spiral profiles.

Horizontal wind retrievals were calculated only in regions where at least two sets of input radial velocities were included in the analysis (Fig. 2), with horizontal winds defaulting to radial velocities otherwise. An example appears in Fig. 2 (Spiral 5 at 2.6 and $7.6 \mathrm{~km}$ MSL). The spiral was located between KUDX and KABR, with slightly better overlapping coverage from KUDX.

The storm motion for the 20 June MCS was determined using the National Severe Storms Laboratory MultiRadar Multi-Sensor Seamless Hybrid Scan Reflectivity (SHSR) product (Zhang et al. 2016). The SHSR $37 \mathrm{dBZ}$ isodop, which was found to be a suitable proxy for overall system morphology, was plotted every $10 \mathrm{~min}$ between 0450 and 0810 UTC 20 June (Fig. 3a), with a best-fit line subjectively drawn through the geometric centroids of each isodop (Fig. 3b). The resulting average storm motion was found to be $(u, v)=(28.5,-1.95)$ $\mathrm{m} \mathrm{s}^{-1}$, and storm-relative winds were determined by subtracting the $u$ and $v$ components of the storm 
TABLE 3. Average RH (\%), and rates of change in RH, $\log _{10} N_{t}, \log _{10} \mathrm{TWC}$, and $D_{\mathrm{mm}}$ with respect to increasing $T$ for select layers within each 20 Jun PECAN spiral as well as the 29 Jun BAMEX spiral.

\begin{tabular}{|c|c|c|c|c|c|c|}
\hline Spiral & Temperature range $\left({ }^{\circ} \mathrm{C}\right)$ & $\overline{\mathrm{RH}}(\%)$ & $d \mathrm{RH} / d T\left(\%{ }^{\circ} \mathrm{C}^{-1}\right)$ & $d \log N_{t} / d T\left(\%{ }^{\circ} \mathrm{C}^{-1}\right)$ & $d \log \mathrm{TWC} / d T\left(\%{ }^{\circ} \mathrm{C}^{-1}\right)$ & $d D_{\mathrm{mm}} / d T\left(\mu \mathrm{m}^{\circ} \mathrm{C}^{-1}\right)$ \\
\hline S1 & $T<-9$ & 112.2 & -1.5 & $-22.4 \%$ & $-4.4 \%$ & +24 \\
\hline \multirow[t]{3}{*}{ S2 } & $T \leq-13$ & 115.5 & -1.1 & $-5.1 \%$ & $-3.6 \%$ & +1 \\
\hline & $-13<T<-9$ & 109.6 & -0.5 & $-21.0 \%$ & $-10.7 \%$ & +345 \\
\hline & $-9 \leq T \leq 0$ & 89.0 & -4.8 & $-15.2 \%$ & $-14.2 \%$ & +28 \\
\hline \multirow[t]{2}{*}{ S3 } & $T<-12$ & 109.3 & -3.3 & $-24.4 \%$ & $-8.6 \%$ & +218 \\
\hline & $T \geq-12$ & 66.6 & -1.9 & $-38.4 \%$ & $-74.8 \%$ & -256 \\
\hline \multirow[t]{3}{*}{ S4 } & $T<-6$ & 109.5 & -1.1 & $-9.0 \%$ & $-4.7 \%$ & -1 \\
\hline & $-6 \leq T<-2.6$ & 103.9 & -1.7 & $-32.7 \%$ & $-7.4 \%$ & +127 \\
\hline & $-2.6 \leq T \leq 0$ & 85.8 & -10.1 & $-36.9 \%$ & $-25.1 \%$ & +552 \\
\hline \multirow[t]{3}{*}{ S5 } & $T<-6$ & 111.4 & -1.2 & $-5.1 \%$ & $-2.8 \%$ & +63 \\
\hline & $-6 \leq T<-2.5$ & 104.1 & -1.0 & $-50.0 \%$ & $-4.1 \%$ & +383 \\
\hline & $-2.5 \leq T \leq 0$ & 93.1 & -4.8 & $-68.2 \%$ & $-57.5 \%$ & -938 \\
\hline \multirow[t]{2}{*}{ S6 } & $T<-2.2$ & 105.2 & -1.1 & $-21.8 \%$ & $-5.2 \%$ & +288 \\
\hline & $-2.2 \leq T \leq 2.3$ & 95.9 & -1.4 & $-48.5 \%$ & $-0.7 \%$ & +889 \\
\hline \multirow[t]{2}{*}{ S7 } & $-11 \leq T<-4.7$ & 102.9 & -1.1 & $-41.4 \%$ & $-17.5 \%$ & +315 \\
\hline & $-3.5 \leq T \leq 0$ & 99.9 & -2.8 & $-97.8 \%$ & $-44.2 \%$ & +195 \\
\hline B1 & $T \leq 2.5$ & 112.2 & -3.2 & $-17.9 \%$ & $-13.6 \%$ & +43 \\
\hline
\end{tabular}

motion vector from the vector components of the observed ground-relative winds.

Data from surrounding WSR-88D radars were combined using the Python ARM Radar Toolkit (Helmus and Collis 2016) to produce a composite radar reflectivity field of the entire MCS at $1 \mathrm{~km}$ AGL. The flight track of the P-3 was plotted at 1-min intervals atop the resulting composited radar reflectivity field, with the maximum range $(71.38 \mathrm{~km})$ of the fore and aft beams of the TDR provided for reference (Fig. 4).

\section{Results}

The 20 June spirals are presented in chronological order, with thermodynamic and microphysical analyses provided in the context of both single radar observations and SAMURAI analyses where available. Characteristics of each 20 June spiral, and the first spiral from the 29 June 2003 BAMEX mission (hereafter referred to as B1), are provided in Table 2, including the starting and ending altitudes, the maximum and minimum values of $T$ and $\mathrm{RH}$, the temperature lapse rate $(d T / d z)$, and $T$ at the top and bottom of the ML (if observed).

\section{a. S1 and S2: TZ/rear inflow notch}

The P-3 completed an upward spiral (S1) followed by a downward spiral (S2) between 0456 and 0513 UTC within the rear inflow notch of the developing bow echo (Fig. 4a). The rear inflow notch appears as a concavity in the trailing edge of the precipitation echo immediately to the northwest of S2 (Fig. 5a), with a channel of weaker reflectivity denoted by the dashed black line in Fig. 5a extending southeast from this region, across the spiral, and toward the convective line. The $\mathrm{S} 2$ cross section of reflectivity in Fig. 6a, location denoted by the solid black line in Fig. 5a, shows that the P-3 began its descent in a region of locally enhanced reflectivity $(18 \mathrm{dBZ})$ at $(x, z)=(35,7.3 \mathrm{~km})$ [all cross-section-specific coordinates are henceforth given as $(x, z)]$. Reflectivities decreased to $12 \mathrm{dBZ}$ at the top of the ML, $(43,4.4 \mathrm{~km})$, rapidly decreasing further within and below the ML to a value of $2 \mathrm{dBZ}$ at the bottom of the $\mathrm{S} 2$ descent. No radar bright band was observed. S1 was only $1.4 \mathrm{~km}$ deep with a maximum $T$ of $-9.3^{\circ} \mathrm{C}$ (not shown) and was characterized by a similar reflectivity structure as observed along the S2 flight track above $6 \mathrm{~km}$ (Fig. 6a).

The location of the RIJ axis in the S2 analysis coincides with the maxima of storm-relative rear-tofront (RTF) flow between approximately $8.8 \mathrm{~km}$ and $3.2 \mathrm{~km} \mathrm{MSL}$ as seen in Fig. 6b. The RIJ had a downward slope from left to right in the resolved wind field, beginning to the left at $(0,7 \mathrm{~km})$ with the terminus presumably located just beyond the region of resolvable winds as it reached the convective line near (120, $4.2 \mathrm{~km}$ ) (Fig. 6a). S2 fully transected the RIJ with aircraft in situ observed ground-relative wind speeds up to $37 \mathrm{~m} \mathrm{~s}^{-1}$ at $3.5 \mathrm{~km} \mathrm{MSL}$, just below the $\mathrm{S} 2 \mathrm{ML}$ at $3.8 \mathrm{~km}$ MSL (Fig. 7). The only other existing observations within the rear inflow notch of an MCS were collected in B1.

Vertical profiles of $N(D)$ and $M(D)$ were used to understand how PSDs varied within each spiral as a function of both time and $T$, with number and mass concentrations for various particle size ranges overlaid to aid in the identification of trends. Considering 


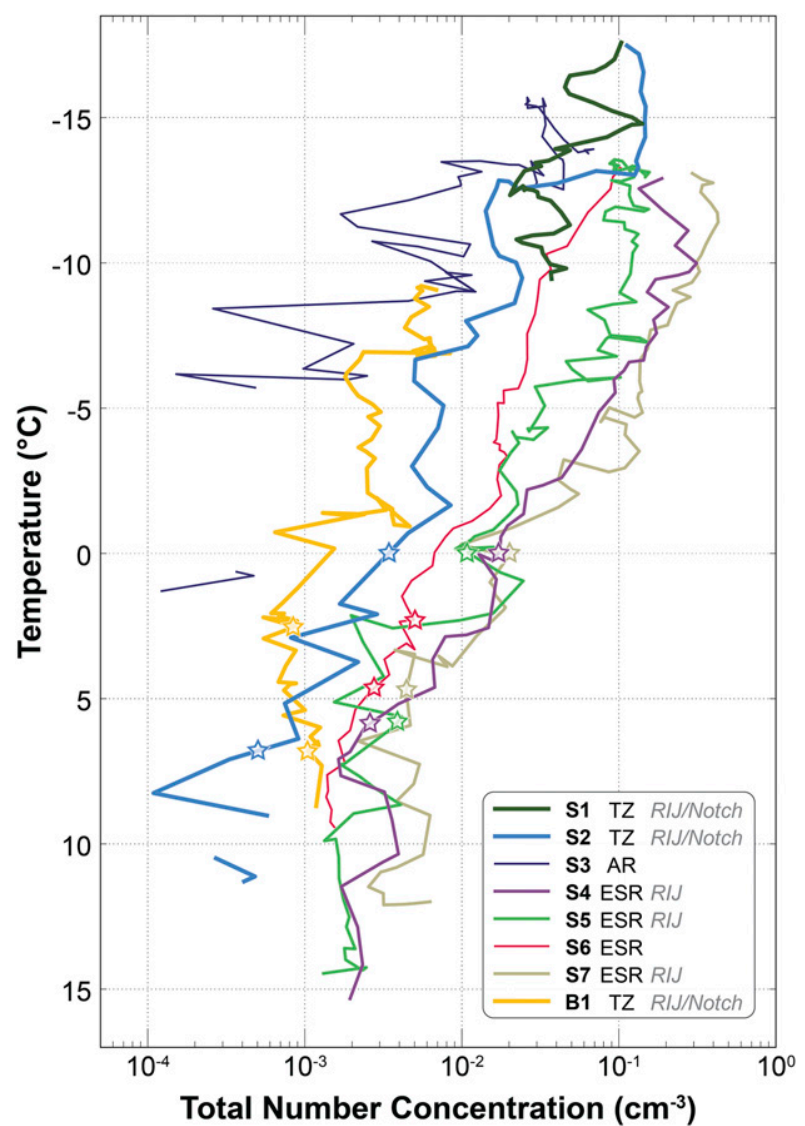

FIG. 9. Total number concentration $\left(N_{t}\right)\left(\mathrm{cm}^{-3}\right)$ as a function of $T\left({ }^{\circ} \mathrm{C}\right)$ for all 20 Jun PECAN spirals along with the first 29 Jun BAMEX spiral. Stars indicate the top and bottom of the ML for each spiral where the ML was observed. The MCS region where each spiral occurred and an indication of whether the given spiral occurred in the vicinity of the RIJ or rear inflow notch of the MCS are provided in the legend.

these profiles for S2 (Fig. 8), $N(D)$ and $M(D)$ predominately decreased with increasing $T$ for $750 \mu \mathrm{m}<$ $D \leq 2 \mathrm{~mm}$ as the P-3 transected the maxima in RIJ flow $\left(-13.2^{\circ} \leq T<-9^{\circ} \mathrm{C}\right)$. Similar decreases in both quantities were observed for $D \leq 750 \mu \mathrm{m}$ to $T \approx-12^{\circ} \mathrm{C}$, at which point $N(D)$ and $M(D)$ for $D \leq 750 \mu \mathrm{m}$ and $2<$ $D \leq 6 \mathrm{~mm}$ increased until reaching the first level of subsaturated air at $T=-9^{\circ} \mathrm{C}$. Between $-13.2^{\circ}$ and $-9^{\circ} \mathrm{C}$, the average $d \log N_{t} / d T$ was $-21.0 \%{ }^{\circ} \mathrm{C}^{-1}$, and $d \log \mathrm{TWC} / d T$ was $-10.7 \%{ }^{\circ} \mathrm{C}^{-1}$ (Table 3 ; Figs. 9 and 10 , respectively). The greater rate of decrease in $N_{t}$ relative to TWC, an increase in median mass diameter $\left(D_{\mathrm{mm}}\right)$ with increasing $T\left(d D_{\mathrm{mm}} / d T\right)$ of $+345 \mu \mathrm{m}^{\circ} \mathrm{C}^{-1}$ (Table 3; Fig. 11), together with the increases in $N(D)$ and $M(D)$ for larger particles and decreases for small particles were all likely due to aggregation. Unexplained "oscillations" in $N(D)$ and $M(D)$ - such as the localized increase in both for $D \leq 2 \mathrm{~mm}$ and decrease for $D>2 \mathrm{~mm}$

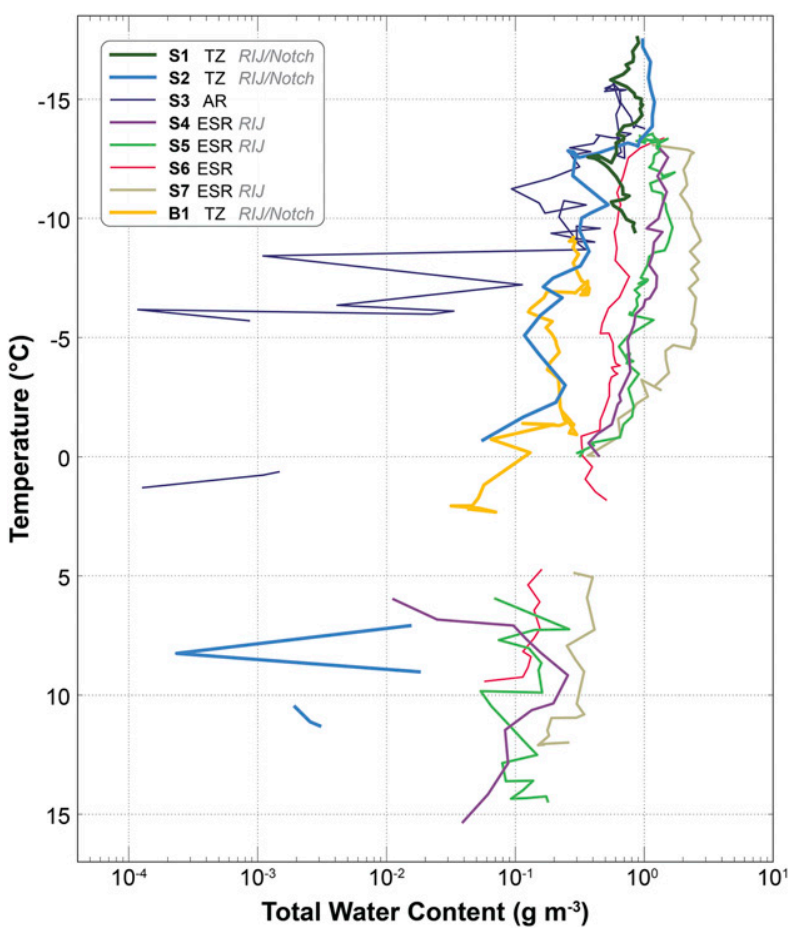

FIG. 10. As in Fig. 9, but for total water content (TWC) $\left(\mathrm{g} \mathrm{m}^{-3}\right)$ as a function of $T\left({ }^{\circ} \mathrm{C}\right)$. Particle mass was not calculated within the ML, thus the data gaps in TWC in the spirals where an ML was observed.

between approximately $-10^{\circ}$ and $-9^{\circ} \mathrm{C}$-were likely due to the P-3 spiraling into and out of distinct particle populations and horizontal inhomogeneity. Similar oscillations were observed in the quasi-Lagrangian BAMEX spirals (M07).

Just below the RIJ flow maxima, an 800-m-thick layer of subfreezing, subsaturated air between the S2 ML at $0^{\circ} \mathrm{C}(4.4 \mathrm{~km} \mathrm{MSL})$ and $T=-6^{\circ} \mathrm{C}(5.2 \mathrm{~km}$ MSL) was observed (Fig. 12). RH decreased at an average rate of $-2.9 \%{ }^{\circ} \mathrm{C}^{-1}$ for $T \leq 0^{\circ} \mathrm{C}$, with a similar trend observed within and below the ML (Table 4), reaching a minimum of $28 \%$ at the bottom of S2. In addition, $\mathrm{S} 2 \mathrm{had}$ the most negative $d T / d z$ of the 20 June spirals, averaging $-7.41^{\circ} \mathrm{C} \mathrm{km}^{-1}$ (Table 4), along with the warmest $T$ of the 20 June spirals for any given altitude below $4.25 \mathrm{~km}$ MSL (Fig. 13). B1 exhibited similar trends in both $\mathrm{RH}$ and $T$ as those seen in S2, with large $d T / d z$ and notably subsaturated conditions, though unlike S2, B1 never achieved saturation at any level. Unique to $\mathrm{S} 2$ and $\mathrm{B} 1$ relative to all other BAMEX and PECAN spirals on any day was the presence of ice observed to $T=+6.8^{\circ} \mathrm{C}$ (Fig. 14; cf. M07). Slight evidence of melting onset within $\mathrm{S} 2$ was found at $0^{\circ} \mathrm{C}$, with observed particles at all $T>0^{\circ} \mathrm{C}$ never resembling entirely liquid drops, suggesting that melting was progressing very 


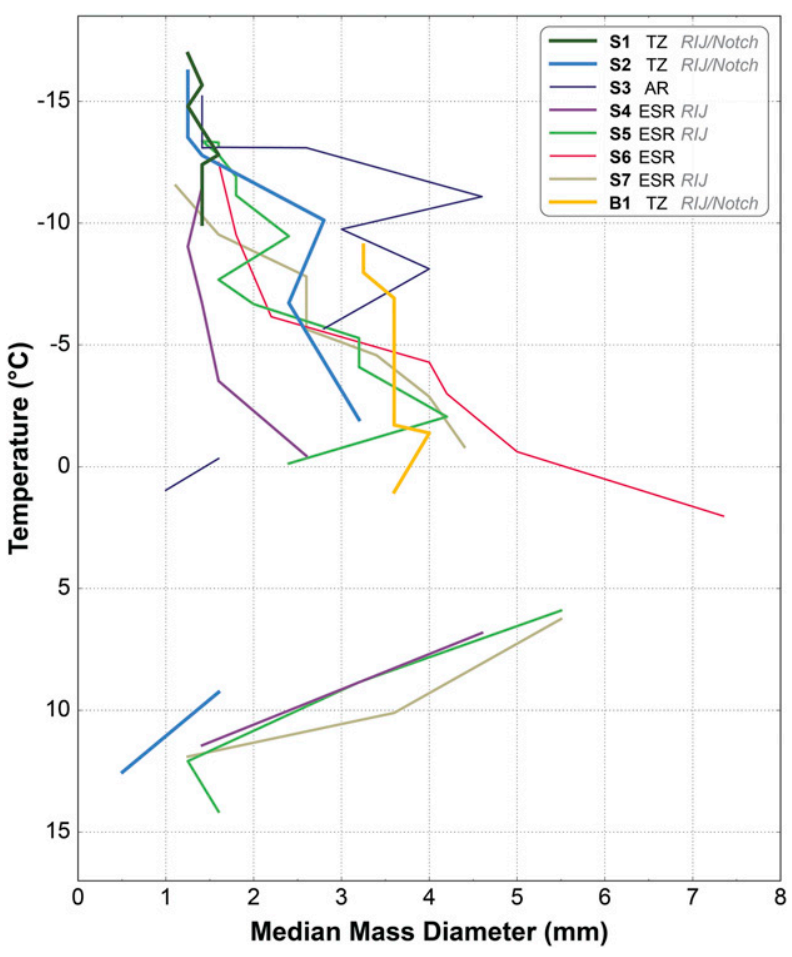

FIG. 11. As in Fig. 9, but for median mass diameter $\left(D_{\mathrm{mm}}\right)(\mathrm{mm})$ as a function of $T\left({ }^{\circ} \mathrm{C}\right)$. Particle mass was not calculated within the ML, thus the data gaps in $D_{\mathrm{mm}}$ in the spirals where an ML was observed.

slowly, due in part to the evaporative/sublimative cooling of particles (e.g., Rasmussen and Pruppacher 1982; M07). Despite thermodynamically similar conditions, B1 exhibited a more definitive melting onset at $T=$ $+2.5^{\circ} \mathrm{C}$, complete with a 250 -m-thick isothermal layer (M07). Three separate isothermal layers, each approximately $75-\mathrm{m}$-thick, were observed within the ML of S2: at melting onset, at $+2.2^{\circ} \mathrm{C}$, and at $+5.5^{\circ} \mathrm{C}$ (Fig. 13). The G09 column model of B1 suggests that microphysical processes alone cannot explain the degree of sustained subsaturation seen within B1, and by extension S2. Mesoscale downdrafts associated with the descending RIJ likely accelerated ice toward warmer $T$ prior to melting, in addition to offsetting the moistening due to sublimation via adiabatic warming. Within S2, the generally greater decrease in $\mathrm{RH}$ with increasing $T$ and a more vigorous RIJ than observed in B1 (Fig. 7) may explain the lack of both well-defined melting and a contiguous isothermal layer at melting onset.

After crossing the first level of subsaturation at $T=-9^{\circ} \mathrm{C}, N(D)$ and $M(D)$ for $D<2 \mathrm{~mm}$ decreased overall with increasing $T$ until reaching the top of the ML. The $N(D)$ and $M(D)$ for $2<D \leq 6 \mathrm{~mm}$ also decreased with increasing $T$, with increases in both

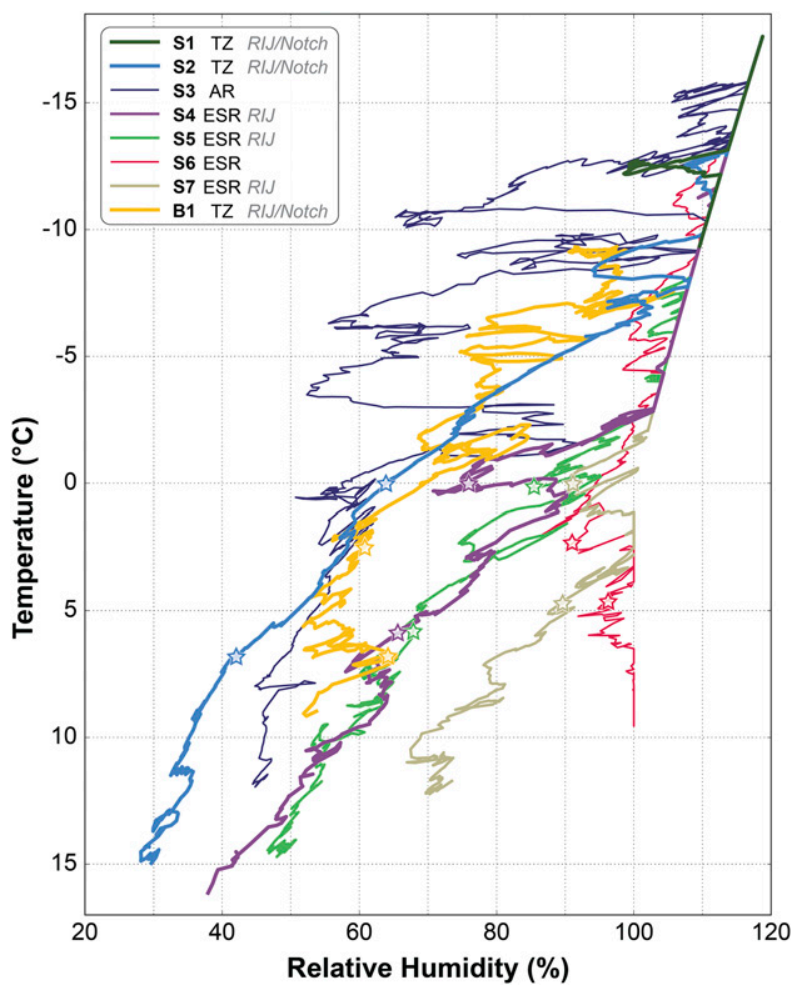

FIG. 12. As in Fig. 9, but for relative humidity (RH) (\%) as a function of $T\left({ }^{\circ} \mathrm{C}\right)$

quantities between $-5^{\circ}$ and $-2.3^{\circ} \mathrm{C}$. For this primarily subsaturated layer within $\mathrm{S} 2 d \log N_{t} / d T$ was $-15.2 \%$ ${ }^{\circ} \mathrm{C}^{-1}$, and $d \log \mathrm{TWC} / d T$ was $-14.2 \%{ }^{\circ} \mathrm{C}^{-1}$ (Figs. 9 and 10, respectively). Aggregation alone would produce an increase in larger particles at the expense of small particles, which is commonly reflected in increases of $D_{\mathrm{mm}}$ with increasing $T$. However, this predominantly subsaturated layer of S2 had a negligible $d D_{\mathrm{mm}} / d T$ of $+28 \mu \mathrm{m}^{\circ} \mathrm{C}^{-1}$ for $T \leq 0^{\circ} \mathrm{C}$ (Fig. 11). These results are similar to those of $\mathrm{B} 1$, though the rates of

TABLE 4. Average rates of change in $\mathrm{RH}$ with respect to increasing $T$, and in $T$ with respect to increasing altitude, for the layers above and below the top of the ML in spirals where the ML was observed on 20 June.

\begin{tabular}{cccc}
\hline \hline Spiral & Temperature range & $d \mathrm{RH} / d T\left(\%{ }^{\circ} \mathrm{C}^{-1}\right)$ & $d T / d z\left({ }^{\circ} \mathrm{C} \mathrm{km}^{-1}\right)$ \\
\hline \multirow{2}{*}{ S2 } & $T \leq 0$ & -2.9 & -5.6 \\
& $T>0$ & -2.4 & -9.4 \\
S4 & $T \leq 0$ & -2.3 & -5.5 \\
& $T>0$ & -2.8 & -8.6 \\
S5 & $T \leq 0$ & -1.5 & -5.5 \\
& $T>0$ & -2.8 & -8.0 \\
S6 & $T \leq 2.3$ & -1.2 & -4.8 \\
& $T>2.3$ & +0.2 & -6.8 \\
S7 & $T \leq 0$ & -1.2 & -5.1 \\
& $T>0$ & -2.8 & -7.7 \\
\hline
\end{tabular}




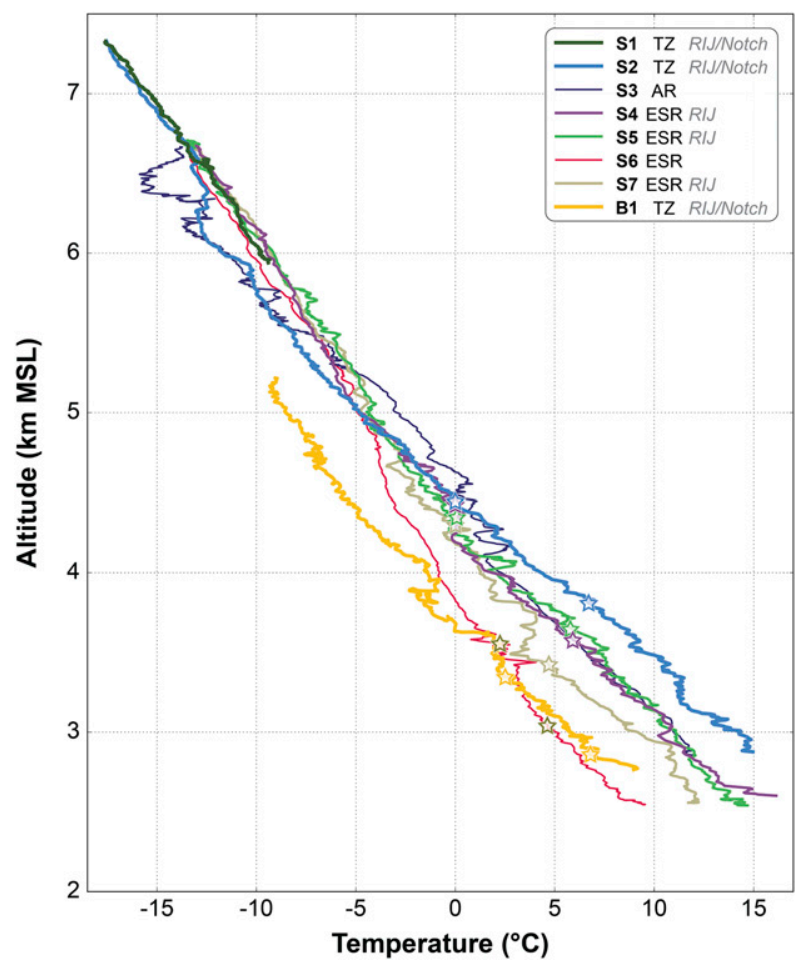

FIG. 13. As in Fig. 9, but for temperature $(T)\left({ }^{\circ} \mathrm{C}\right)$ as a function of altitude (km MSL).

reduction in $N_{t}$ and TWC, and rate of increase in $D_{\mathrm{mm}}$ with increasing $T$ were lower than seen in $\mathrm{S} 2$, at $-12.7 \%{ }^{\circ} \mathrm{C}^{-1},-5.8 \%{ }^{\circ} \mathrm{C}^{-1}$, and $+67 \mu \mathrm{m}^{\circ} \mathrm{C}^{-1}$, respectively, for $T \leq 0^{\circ} \mathrm{C}$. All of this taken together would suggest that while aggregation was definitely occurring within S2, sublimation may have limited aggregation efficiency by both reducing the number of smaller particles (e.g., Gu and Liou 2000), and reducing the size of larger particles and existing aggregates. The absence of a water layer on the particles could also have reduced the aggregation efficiency.

\section{b. S3: Rear anvil}

An upward spiral (S3) commenced between 0521 and 0537 UTC sampling the anvil region to the north of the RIJ axis (Fig. 4b). TDR reflectivity revealed that S3 predominantly sampled clear air beneath the anvil, with sporadic cloud sampling near cloud base for $-6^{\circ} \geq T \geq-12^{\circ} \mathrm{C}$, and remained within the lower $\sim 400 \mathrm{~m}$ of the anvil for the rest of the ascent at $T<-12^{\circ} \mathrm{C}$.

For $T<-12^{\circ} \mathrm{C}, N(D)$ and $M(D)$ generally decreased with increasing $T$ for $D \leq 2 \mathrm{~mm}$, while both exhibited increases for $D>2 \mathrm{~mm}$. Here, a greater decrease in $\log N_{t}$ than $\log$ TWC relative to increasing $T$ was observed, with a $d \log N_{t} / d T$ of $-24.4 \%{ }^{\circ} \mathrm{C}^{-1}$ and a

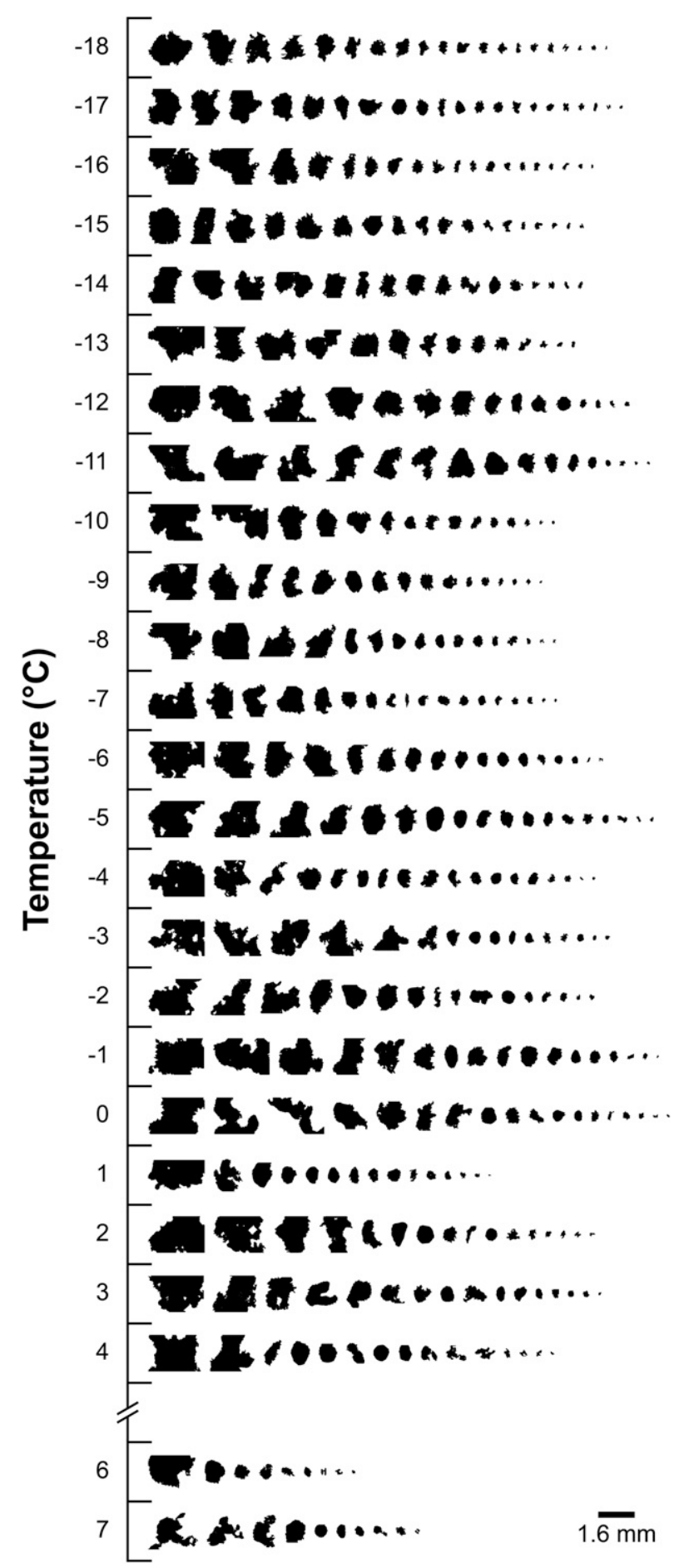

FIG. 14. Representative particle images observed by the CIP during $\mathrm{S} 2$ as a function of $T\left({ }^{\circ} \mathrm{C}\right)$.

$d \log \mathrm{TWC} / d T$ of $-8.6 \%{ }^{\circ} \mathrm{C}^{-1}$ (Figs. 9 and 10 , respectively). These trends, coupled with an average $d D_{\mathrm{mm}} / d T$ of $+218 \mu \mathrm{m}^{\circ} \mathrm{C}^{-1}$ (Fig. 11) and aggregates observed in the CIP particle imagery, support aggregation as an 

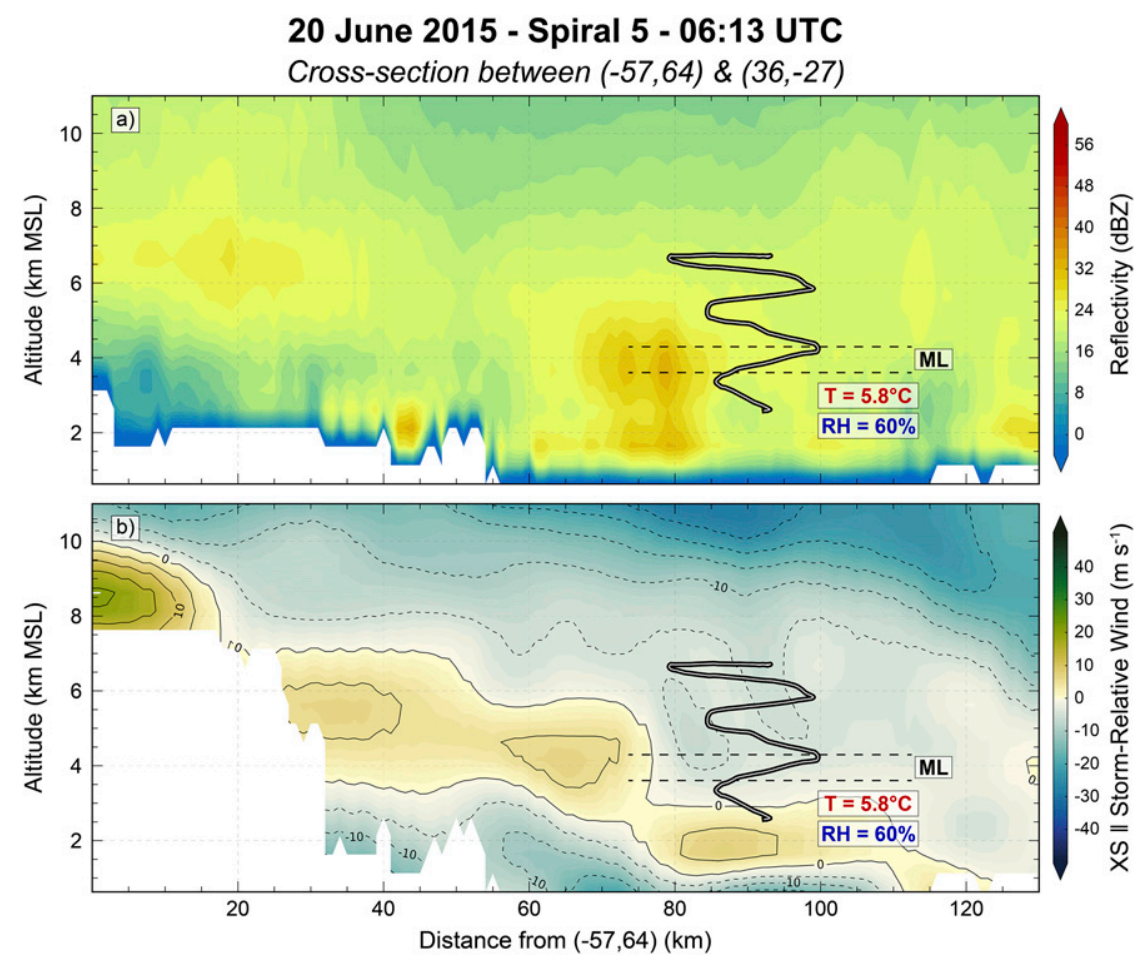

FIG. 15. As in Fig. 6, but for the S5 vertical cross section given by the solid black line in Fig. 5b.

active process within the anvil region. A 250-m-thick layer of subsaturated air was observed for $-12^{\circ}>$ $T>-13^{\circ} \mathrm{C}$ (Fig. 12), where $N(D)$ and $M(D)$ decreased over most particle sizes, suggesting a limiting effect on aggregation due to sublimation.

\section{c. S4 and S5: Trailing ESR/RIJ}

The P-3 conducted downward and upward spirals (S4 and S5) between 0547 and 0622 UTC in the trailing half of the ESR, drifting eastward in an attempt to maintain a quasi-steady position relative to the convective line (Figs. 4c,d). Weak storm-relative convergence was observed along the southeastern half of the cross section (Fig. 5b), with cyclonic flow inferred to the northeast of the cross section and less-structured anticyclonic flow to the southwest, suggesting bookend vortices may have been present or developing at this time. TDR data showed that while the overall structure between the two spirals was the same, there was considerable alongtrack variability in reflectivity within both S4 and S5. Given the resolution of the SAMURAI analyses is large compared to the small scale over which variations were observed, the S5 analysis presented here will also be considered as the basis for the interpretation of S4.

The cross section of reflectivity indicates that S4 and S5 occurred within the ESR, based on the presence of a weak radar bright band at $(78,3.8 \mathrm{~km})$, and precipitation reaching the surface between $x=55$ and $115 \mathrm{~km}$ (Fig. 15a). Of note is the greater downward slope seen in the RIJ flow in the S5 storm-relative winds (Fig. 15b) compared to that of S2 (Fig. 6b), with the axis of highest wind speeds beginning at $(0,8.5 \mathrm{~km})$ and reaching the surface at $x=$ $115 \mathrm{~km}$; a total descent of $7.9 \mathrm{~km}$, compared to only $2.8 \mathrm{~km}$ in $\mathrm{S} 2$ where the RTF flow remained elevated. The P-3 predominantly sampled the relatively quiescent flow at the lower fringes of the FTR flow during S4 and S5, which ascended from right to left above the RTF flow and RIJ, only encountering RTF flow in the lowest $500 \mathrm{~m}$ of each spiral. During this period, damaging straight line winds were reported at the surface $100 \mathrm{~km}$ to the east-southeast of S4 and S5, with large tree branches down, a pickup truck flipped, and destruction of a mobile home resulting in a fatality (https:// www.spc.noaa.gov/climo/reports/150619_rpts.html). Winds beneath the S4 and S5 ML (3.7 km MSL) were as high as $36 \mathrm{~m} \mathrm{~s}^{-1}$ at $3.4 \mathrm{~km} \mathrm{MSL} \mathrm{(Fig.} \mathrm{7).}$

The average value of $d T / d z$ over S4 and S5 was less negative than observed in $\mathrm{S} 2$, at $-6.61^{\circ} \mathrm{C} \mathrm{km}^{-1}$ and $-6.47^{\circ} \mathrm{C} \mathrm{km}^{-1}$, respectively. The $\mathrm{S} 4$ and $\mathrm{S} 5 d T / d z$ became more negative by $-2.6^{\circ} \mathrm{C} \mathrm{km}^{-1}$ on average for $T>0^{\circ} \mathrm{C}$, when compared to $T \leq 0^{\circ} \mathrm{C}$ (Fig. 13). The subfreezing/subsaturated layer observed in S2 was also present in S4 and S5, though at this time and location the depth of this layer had decreased to $270 \mathrm{~m}$ in $\mathrm{S} 4$ and 


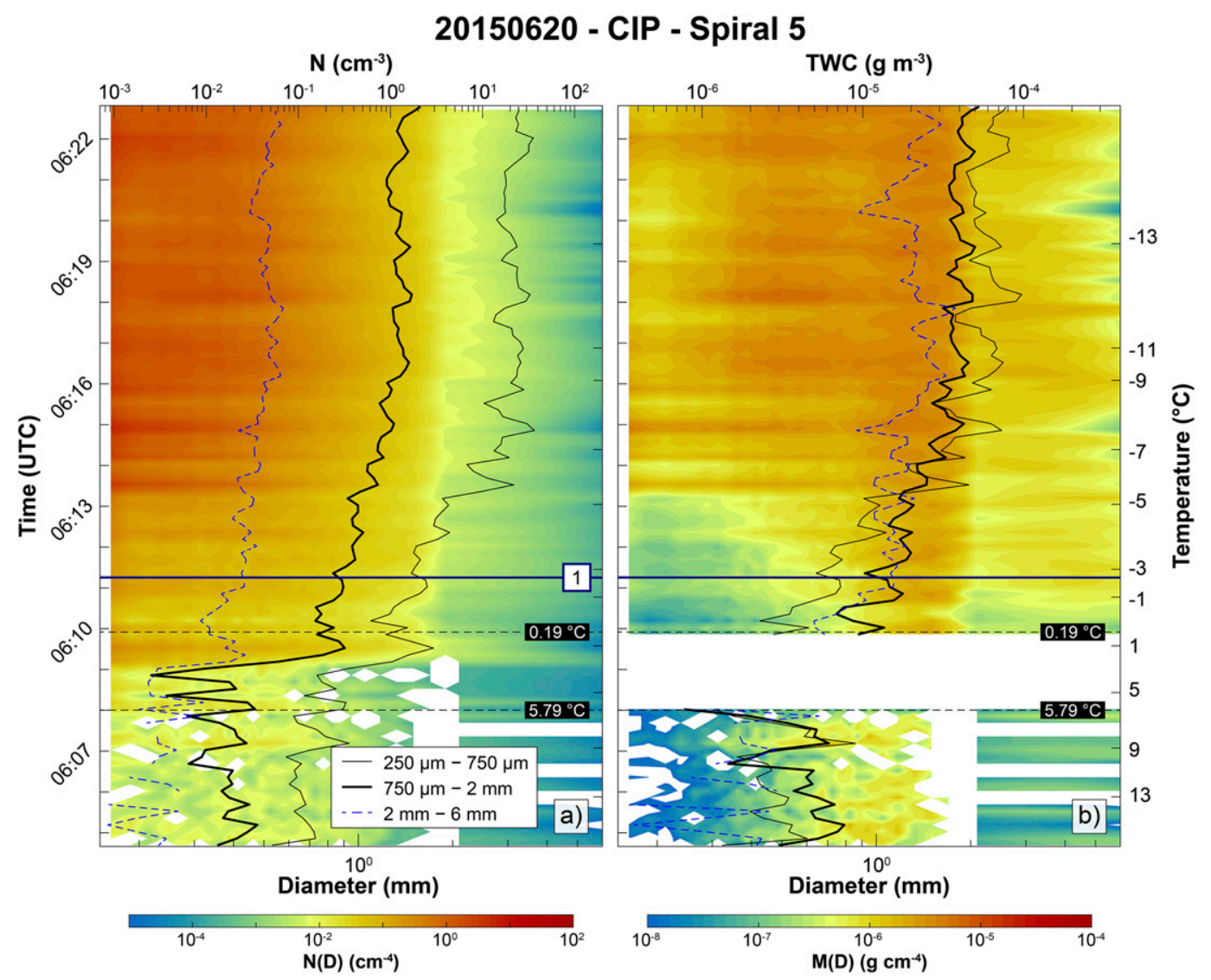

FIG. 16. As in Fig. 8, but for S5. The dark blue horizontal line labeled as "1" in each panel refers to the top of the subsaturated layer.

$310 \mathrm{~m}$ in S5 (Fig. 12). In addition, $\mathrm{RH}$ decreased at rates of $-2.6 \%{ }^{\circ} \mathrm{C}^{-1}$ and $-2.1 \%{ }^{\circ} \mathrm{C}^{-1}$ within and below the MLs of S4 and S5, respectively, with minima of 37.9\% and $46.6 \%$. These observed thermodynamic changes are consistent with an inferred change in latent cooling across and below the ML (G09).

Similar to the preceding spirals, aggregates of largely indeterminable shape dominated those particles observed by the CIP through S4 and S5. Both spirals exhibited isothermal layers at melting onset, with a depth of $215 \mathrm{~m}(230 \mathrm{~m})$ in S4 (S5), and ice was observed to $+5.9^{\circ} \mathrm{C}\left(+5.8^{\circ} \mathrm{C}\right)$.

The vertical profiles of $N(D)$ and $M(D)$ for S4 and S5 shared the same overall distributions and trends, with both spirals exhibiting numerous localized oscillations most likely attributable to the horizontal inhomogeneity revealed in the along-track TDR reflectivity. For brevity, only the $\mathrm{S} 5$ profiles of $N(D)$ and $M(D)$ are discussed here (Fig. 16). For $T<-6^{\circ} \mathrm{C}, N(D)$ and $M(D)$ generally exhibited slight decreases with increasing $T$ across all particle sizes. The vertical profiles of $N_{t}$ and TWC for S5 (S4) similarly reveal modest decreases in both quantities with increasing $T$ over the same layer, with a $d \log N_{t} / d T$ of $-5.1(-9.0) \%{ }^{\circ} \mathrm{C}^{-1}$ and a $d \log T \mathrm{WC} / d T$ of -2.8 (-4.7)\% ${ }^{\circ} \mathrm{C}^{-1}$ (Figs. 9 and 10, respectively). Over the same range, $D_{\mathrm{mm}}$ increased slowly at $+63 \mu \mathrm{m}^{\circ} \mathrm{C}^{-1}$ within S5, with effectively no trend observed within S4 (Fig. 11).

For $-6^{\circ} \leq T<-2.5^{\circ} \mathrm{C}, N(D)$ and $M(D)$ decreased with increasing $T$ for $D \leq 2 \mathrm{~mm}$, most notably for $D \leq$ $750 \mu \mathrm{m}$, with no perceptible trend in either quantity for $2<D \leq 6 \mathrm{~mm}$. The sudden decrease in $N(D)$ for small particles within S5 manifest as a $d \log N_{t} / d T$ of $-50 \%{ }^{\circ} \mathrm{C}^{-1}$-an order of magnitude difference from the same quantity for $T<-6^{\circ} \mathrm{C}$-while $d \log \mathrm{TWC} /$ $d T$ changed only marginally to $-4.1 \%{ }^{\circ} \mathrm{C}^{-1}$. A similar change was observed in the $d \log N_{t} / d T$ and $d \log T W C / d T$ of S4 for $-6^{\circ} \leq T<-2.6^{\circ} \mathrm{C}$, with values of $-32.7 \%$ ${ }^{\circ} \mathrm{C}^{-1}$ and $-7.4 \%{ }^{\circ} \mathrm{C}^{-1}$, respectively. The considerable decreases in $N_{t}$ and comparatively small decreases in TWC over these ice-supersaturated layers in S4 and S5 were concurrent with values of $d D_{\mathrm{mm}} / d T$ of $+383 \mu \mathrm{m}^{\circ} \mathrm{C}^{-1}$ and $+127 \mu \mathrm{m}^{\circ} \mathrm{C}^{-1}$, respectively. Taken together with the decrease in $N(D)$ and $M(D)$ of small 
particles, these trends are consistent with aggregation, though a cause for the absence of any appreciable trend in the distribution of larger particles is unknown.

For $-2.5^{\circ} \leq T \leq 0^{\circ} \mathrm{C}$, the subfreezing/subsaturated layer above the S5 ML, $N(D)$ and $M(D)$ decreased with increasing $T$ across all particle sizes, though preferentially so for $D<1 \mathrm{~mm}$. The value of $d \log N_{t} / d T$ over this layer became slightly more negative at $-68.2 \%{ }^{\circ} \mathrm{C}^{-1}$ while TWC began to decrease at a far greater rate than observed above, with a $d \log \mathrm{TWC} / d T$ of $-57.5 \%{ }^{\circ} \mathrm{C}^{-1}$. Given these changes, coupled with a $d D_{\mathrm{mm}} / d T$ of nearly $-1 \mathrm{~mm}^{\circ} \mathrm{C}^{-1}$, sublimation was likely limiting the effects of aggregation over this layer by aiding in the reduction of small particles and countering the growth of larger particles. The subfreezing/subsaturated layer above the S4 ML $\left(-2.6^{\circ} \leq T \leq 0^{\circ} \mathrm{C}\right)$ exhibited similar changes in $d \log N_{t} / d T$ and $d \log \mathrm{TWC} / d T$, with greater rates of decrease $\left(-36.9 \%{ }^{\circ} \mathrm{C}^{-1}\right.$ and $-25.1 \%{ }^{\circ} \mathrm{C}^{-1}$, respectively) than observed above this layer. However, increases in the S4 $N(D)$ and $M(D)$ for $D>2 \mathrm{~mm}$ between the ML top and $T=-0.6^{\circ} \mathrm{C}$ (not shown) yielded a locally sharp increase in $D_{\mathrm{mm}}$, and subsequently modified the average $d D_{\mathrm{mm}} / d T$ over the whole layer to $+552 \mu \mathrm{m}^{\circ} \mathrm{C}^{-1}$. As previously noted, it is expected that such differences within and between $\mathrm{S} 4$ and S5 are likely attributable to horizontal inhomogeneity and the sampling of different particle populations.

\section{d. S6: Non-RIJ ESR}

The P-3 conducted a downward spiral (S6) between 0638 and 0647 UTC sampling the expansive stratiform region north of S4 and S5 (Fig. 4e). A well-defined bright band was observed in the TDR reflectivity at this time, aligned with the location of the ML as defined using particle imagery. S6 was the only 20 June ESR spiral that did not sample within the RIJ, and had the lowest wind speeds observed among all 20 June spirals at all altitudes, reaching a maximum of $19 \mathrm{~m} \mathrm{~s}^{-1}$ at $5.7 \mathrm{~km} \mathrm{MSL}$, and maximum wind speeds below the ML $(3.05 \mathrm{~km}$ MSL) of $14 \mathrm{~m} \mathrm{~s}^{-1}$ at $2.8 \mathrm{~km} \mathrm{MSL} \mathrm{(Fig.} \mathrm{7).}$

Removed from the drying and warming impacts of the RIJ, S6 had the lowest $d T / d z$ of $-5.17^{\circ} \mathrm{Ckm}^{-1}$ (Fig. 13), and was far moister than the other 20 June spirals, particularly evident within and below the ML where RH averaged $99 \%$ (Fig. 12). In addition, S6 exhibited a delay in the onset of melting to $T=+2.3^{\circ} \mathrm{C}$ (Fig. 17), associated with a 750-m-thick layer of subsaturated air between the ML top and $T=-2.2^{\circ} \mathrm{C}$. When melting finally commenced, it was accompanied by a 100 -m-thick isothermal layer at $T=+2.3^{\circ} \mathrm{C}$, and another at $+3^{\circ} \mathrm{C}$ of $164 \mathrm{~m}$ depth. These thermodynamic characteristics were unique compared to the other 20 June spirals.

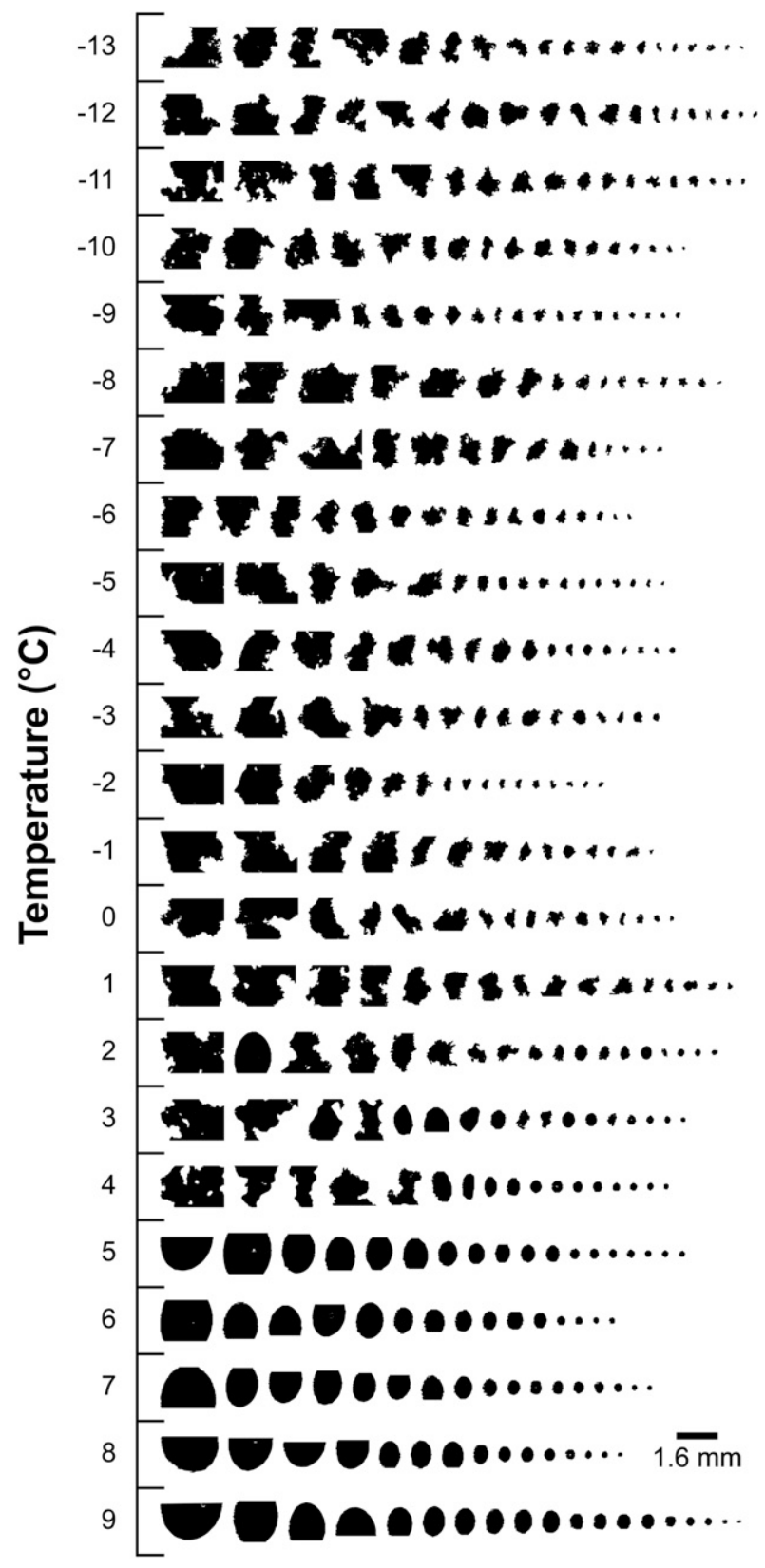

FIG. 17. As in Fig. 14, but for S6.

The vertical profiles of $N(D)$ and $M(D)$ for S6 (Fig. 18) from $T=-12.5^{\circ} \mathrm{C}$ to $T=-2.24^{\circ} \mathrm{C}$, where $\mathrm{RH}$ fell below $100 \%$, indicated decreases in values for $D \leq$ $2 \mathrm{~mm}$, with effectively no trend in either for $D>2 \mathrm{~mm}$. The vertical profile of $D_{\mathrm{mm}}$ over the same layer exhibited an increase of $+288 \mu \mathrm{m}^{\circ} \mathrm{C}^{-1}$ with increasing $T$ (Fig. 11). This, considered along with the more negative values of $d \log N_{t} / d T$ relative to $d \log T W C / d T$ similarly observed in the other 20 June spirals, suggests that aggregation was a dominant process controlling the PSDs within this layer. 


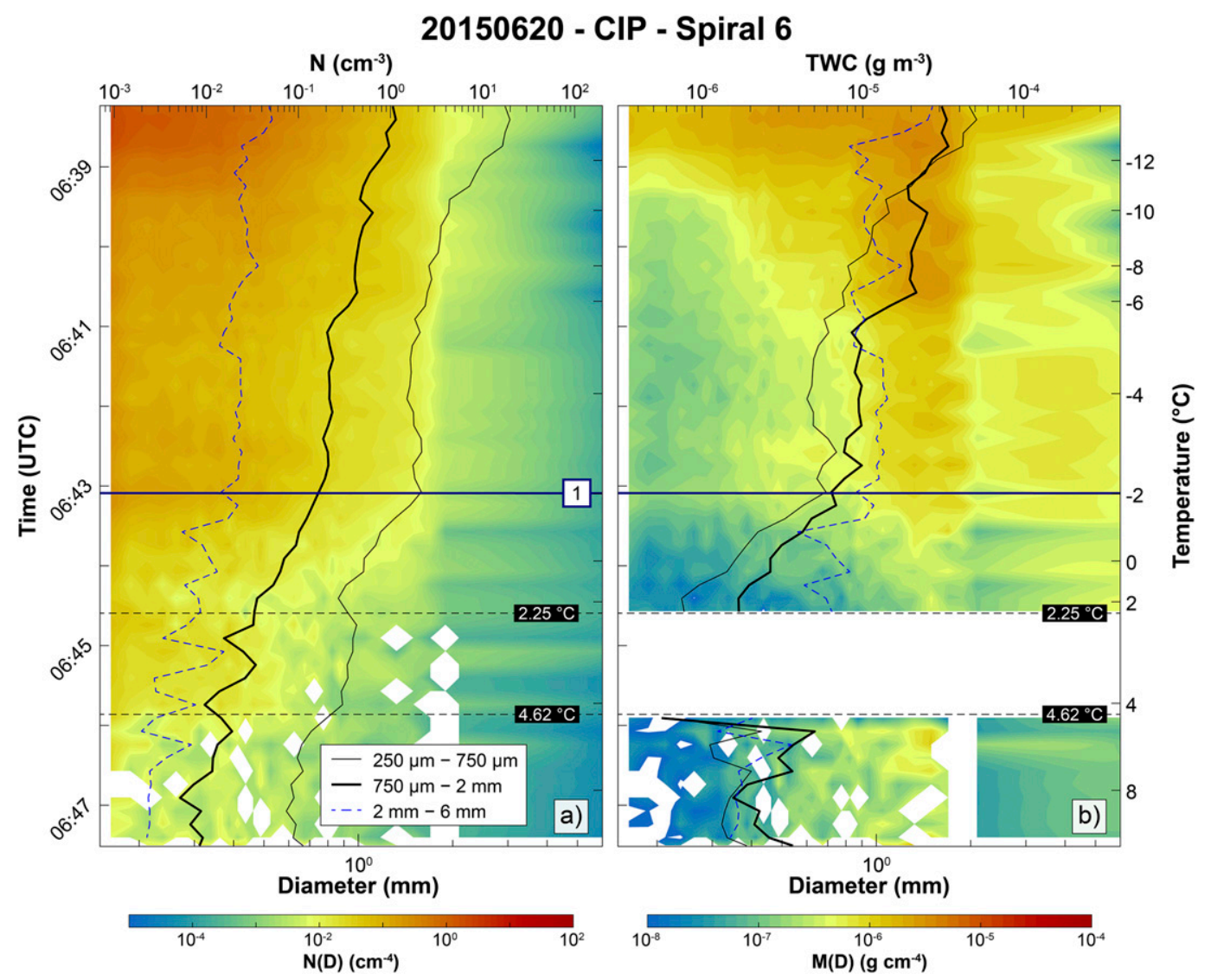

FIG. 18. As in Fig. 8, but for S6. The dark blue horizontal line labeled as "1" in each panel refers to the top of the subsaturated layer.

Within the subsaturated layer above the $\operatorname{ML}\left(-2.24^{\circ} \leq\right.$ $T \leq 2.25^{\circ} \mathrm{C}$ ), both $N(D)$ and $M(D)$ continued to decrease with increasing $T$ for all $D \leq 6 \mathrm{~mm}$, with greater reductions in both quantities for progressively smaller particles. Over the same layer, $D_{\mathrm{mm}}$ increased at a much greater rate of $+889 \mu \mathrm{m}^{\circ} \mathrm{C}^{-1}$, indicating an increase in the mass concentration of larger particles, while a more negative $d \log N_{t} / d T\left(-48.5 \%{ }^{\circ} \mathrm{C}^{-1}\right)$ than seen in the saturated layer above $\left(-21.8 \%{ }^{\circ} \mathrm{C}^{-1}\right)$ is consistent with the decrease in the number of smaller particles due to aggregation. While the subsaturated environment would support sublimation as an active process, the near-zero value of $d \log T W C / d T$ over this layer suggests other processes and/or the sampling of different particle populations are to blame.

\section{e. S7: Leading ESR/RIJ}

Between 0709 and 0746 UTC the P-3 sampled along the northern convective line and immediately behind the bowing segment at $2.5 \mathrm{~km}$ MSL and observed the highest flight-level wind speed on this day of $43 \mathrm{~m} \mathrm{~s}^{-1}$ while crossing the RIJ axis just prior to the final upward spiral (S7) (Fig. 4f). S7 began its ascent within the aforementioned wind maxima at the leading edge of the ESR at 0746, just west of a well-defined TZ with the convective line within the $\sim 70-\mathrm{km}$ range of the TDR (Fig. 5c). Though still not fully resolved, the bookend vortices present in the S5 analysis were far more pronounced in the S7 storm-relative wind field, with a cyclonic circulation centered at approximately $x, y=(25,55 \mathrm{~km})$, and anticyclonic circulation centered at approximately $x, y=(35,5 \mathrm{~km})$.

The S7 ML was observed between approximately 3.4 and $4.25 \mathrm{~km}$ MSL based on particle imagery and aligned well with the radar brightband signature in the S7 cross section (Fig. 19a). A 145-m-deep isothermal layer was observed at melting onset, similar to, though shallower than that observed in S4 and S5 (Fig. 13). Ice was observed as warm as $T=+4.7^{\circ} \mathrm{C}$ (Fig. 20) - the coolest $T$ of melting completion of any of the RIJ spirals. At this time and location, the resolved RIJ flow was of a greater magnitude than observed in either S2 or S5, with stormrelative winds parallel to the cross-section plane peaking at $15 \mathrm{~m} \mathrm{~s}^{-1}$ at $(105,2.4 \mathrm{~km})$ (Fig. 19b), and a maximum 

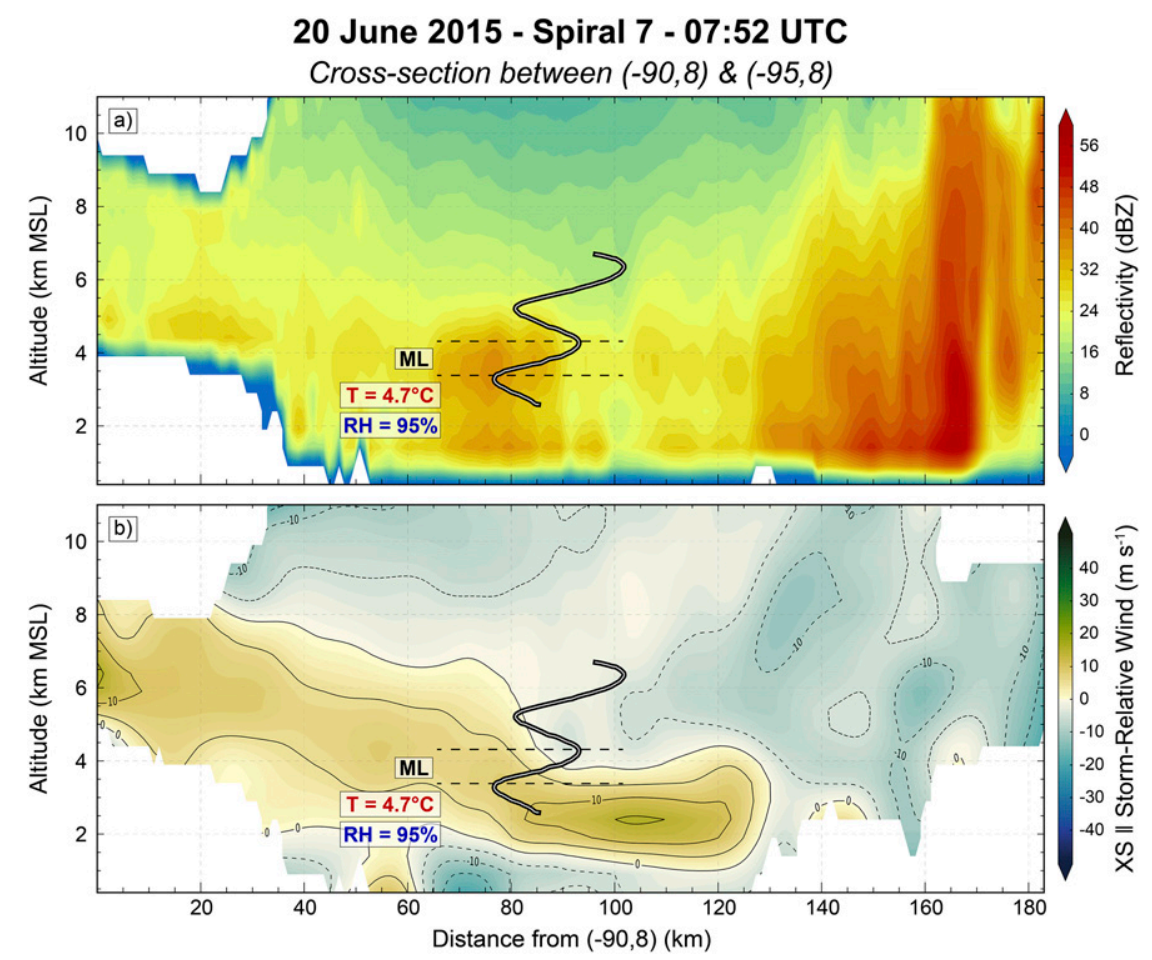

FIG. 19. As in Fig. 6, but for the S7 vertical cross section given by the solid black line in Fig. 5c.

ground-relative horizontal wind speed of $46 \mathrm{~m} \mathrm{~s}^{-1}$ at the same location (Fig. 7). The RIJ descended from (0, $6.4 \mathrm{~km})$ to at least $(130,2.4 \mathrm{~km})$, with descent to the surface either absent or unresolved by the analysis.

S7 was the moistest of the ESR RIJ spirals, with an average RH of $97 \%$ within, and $76 \%$ below, the ML (Fig. 12). Despite at least $3 \mathrm{~h}$ of precipitation echo above the S7 ML, as indicated by radar observations of the storm-relative location of S7, a 100-m-deep subfreezing/subsaturated layer remained above the ML by the time of in situ observation; much shallower than similar layers observed in S2, S4, and S5. In addition, the average $d T / d z$ over the depth of $\mathrm{S} 7$ was $-6.0^{\circ} \mathrm{C} \mathrm{km}^{-1}$, with only the non-RIJ ESR spiral S6 having a lower rate of change (Fig. 13).

Within the top $400 \mathrm{~m}$ of $\mathrm{S} 7\left(-13.2^{\circ} \leq T<-11^{\circ} \mathrm{C}\right)$, $N(D)$ and $M(D)$ increased slightly with increasing $T$ for $D \leq 750 \mu \mathrm{m}$, while decreasing for $2<D \leq 6 \mathrm{~mm}$ (Fig. 21). Immediately beneath this top layer, for $-11^{\circ} \leq T<-4.7^{\circ} \mathrm{C}$, values of $N(D)$ and $M(D)$ decreased with increasing $T$ for $D \leq 750 \mu \mathrm{m}$, remained relatively unchanged for $750 \mu \mathrm{m}<D \leq 2 \mathrm{~mm}$, and increased for $2<D \leq 6 \mathrm{~mm}$. Overall, both $N_{t}$ and TWC decreased with increasing $T$ over this layer (Figs. 9 and 10 , respectively), with $d \log N_{t} / d T$ more than double $d \log \mathrm{TWC} / d T$, at $-41.4 \%{ }^{\circ} \mathrm{C}^{-1}$ and $-17.5 \%{ }^{\circ} \mathrm{C}^{-1}$, respectively. A concurrent $d D_{\mathrm{mm}} / d T$ of $+315 \mu \mathrm{m}{ }^{\circ} \mathrm{C}^{-1}$ (Fig. 11) suggests that aggregation was likely the dominant process affecting the evolution of the particle spectra, as in the saturated layers of the other 20 June spirals.

A brief increase in values of $N(D)$ and $M(D)$ occurred between $-4.7^{\circ}$ and $-3.5^{\circ} \mathrm{C}$ for $250 \mu \mathrm{m} \leq D \leq$ $2 \mathrm{~mm}$, with decreasing values for both quantities for $2<D \leq 6 \mathrm{~mm}$. A lack of any obvious changes in reflectivity or horizontal flow in Fig. 19, coupled with persistently saturated conditions, suggests the P-3 temporarily spiraled into a different particle population over this layer.

For $-3.5^{\circ} \leq T \leq 0^{\circ} \mathrm{C}, N(D)$ and $M(D)$ decreased across all particle sizes, most notably for $250 \mu \mathrm{m} \leq D \leq$ $2 \mathrm{~mm}$. On average, the magnitudes of both $d \log N_{t} / d T$ and $d \log \mathrm{TWC} / d T$ were $-97.8 \%{ }^{\circ} \mathrm{C}^{-1}$ and $-44.2 \%{ }^{\circ} \mathrm{C}^{-1}$, respectively; more than twice the rates of decrease observed in the layer between $-11^{\circ}$ and $-4.7^{\circ} \mathrm{C}$, while approximately maintaining proportionality to each other. This suggests aggregation occurred more readily through this layer, though the observed decrease in $d D_{\mathrm{mm}} / d T$ to $+195 \mu \mathrm{m}^{\circ} \mathrm{C}^{-1}$ implies other factors may have contributed to limiting particle growth. These properties were observed as the P-3 flew near the boundary between the RTF and FTR flow along the upper extent of the enhanced reflectivity gradient associated with the bright band signature, which complicates the interpretation of such deviations from expected trends. 


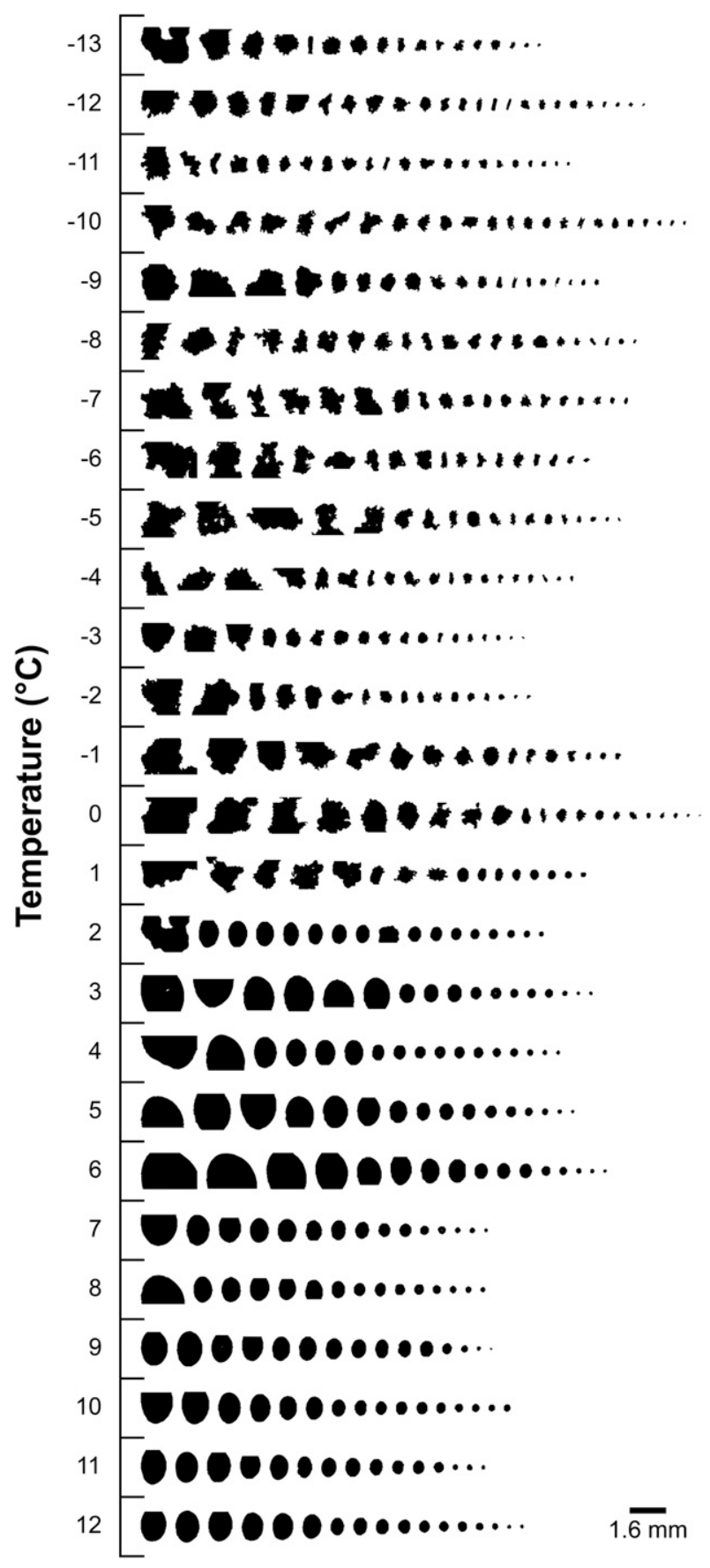

FIG. 20. As in Fig. 14, but for S7.

At $-1.6^{\circ} \mathrm{C}$ (4.4 km MSL), RH dropped below $100 \%$ accompanied by enhanced decreases in both $N(D)$ and $M(D)$, particularly for $250 \leq D \leq 750 \mu \mathrm{m}$, as sublimation was likely preferentially reducing the number and mass of smaller particles while also limiting aggregational growth for larger particles. The net effect of sublimation on aggregational growth within S7 was likely less than in S2, S4, and S5, where subsaturated conditions were observed over greater depths for $T \leq 0^{\circ} \mathrm{C}$.

\section{Discussion and conclusions}

This study used airborne in situ observations from seven spiral profiles within the 20 June 2015 PECAN MCS, along with airborne and ground-based radar observations, to characterize the microphysical and thermodynamic properties within three primary MCS regions (TZ, ESR, and anvil region). Five of these spirals were within or near the main axis of the RIJ, and when compared to each other and the two non-RIJ spirals, provided an opportunity to consider how the thermodynamic and microphysical characteristics vary within and removed from the RIJ, in time, vertically, and relative to the ML. The primary findings of this study are as follows:

1) Aggregates were observed for $T<0^{\circ} \mathrm{C}$ within every profiled region of the 20 June MCS. Aggregation was frequently reflected in the increase of the number and mass of large particles $(D>2 \mathrm{~mm})$ with decreases in both quantities for smaller particles $(250 \mu \mathrm{m} \leq D \leq 2 \mathrm{~mm})$. In these cases, $N_{t}$ decreased at a greater rate than TWC with increasing $T$, along with generally increasing $D_{\mathrm{mm}}$. Taken together, these characteristics are representative of the growth of aggregates primarily at the expense of small particles. These trends were not consistently observed in all layers, likely due to the limiting effects of sublimation on aggregation, and/or potentially the sampling of different particle populations.

2) The ML was found to act as an important and distinct thermodynamic boundary in each of the spirals where an ML was observed, whereby differing rates of change in $T$ and $\mathrm{RH}$ were observed from above to below the ML, due to latent cooling focused immediately above, within, and below the ML. Overall, $T$ decreased more with increasing altitude below the ML than above it. The changes in the rate of moistening from above to below the ML are consistent with the results of the G09 column model study, which showed that saturation is achieved faster above the ML than below within any region of an MCS. G09 found that the change in the rate of moistening occurred across the ML and was directly attributable to the reduction in particle mass per volume air below the ML due to the greater terminal fall speeds of rain than that of ice. As such, sublimation was able to act over greater concentrations of ice particles, increasing $\mathrm{RH}$ faster than below the ML, where relatively less moistening 


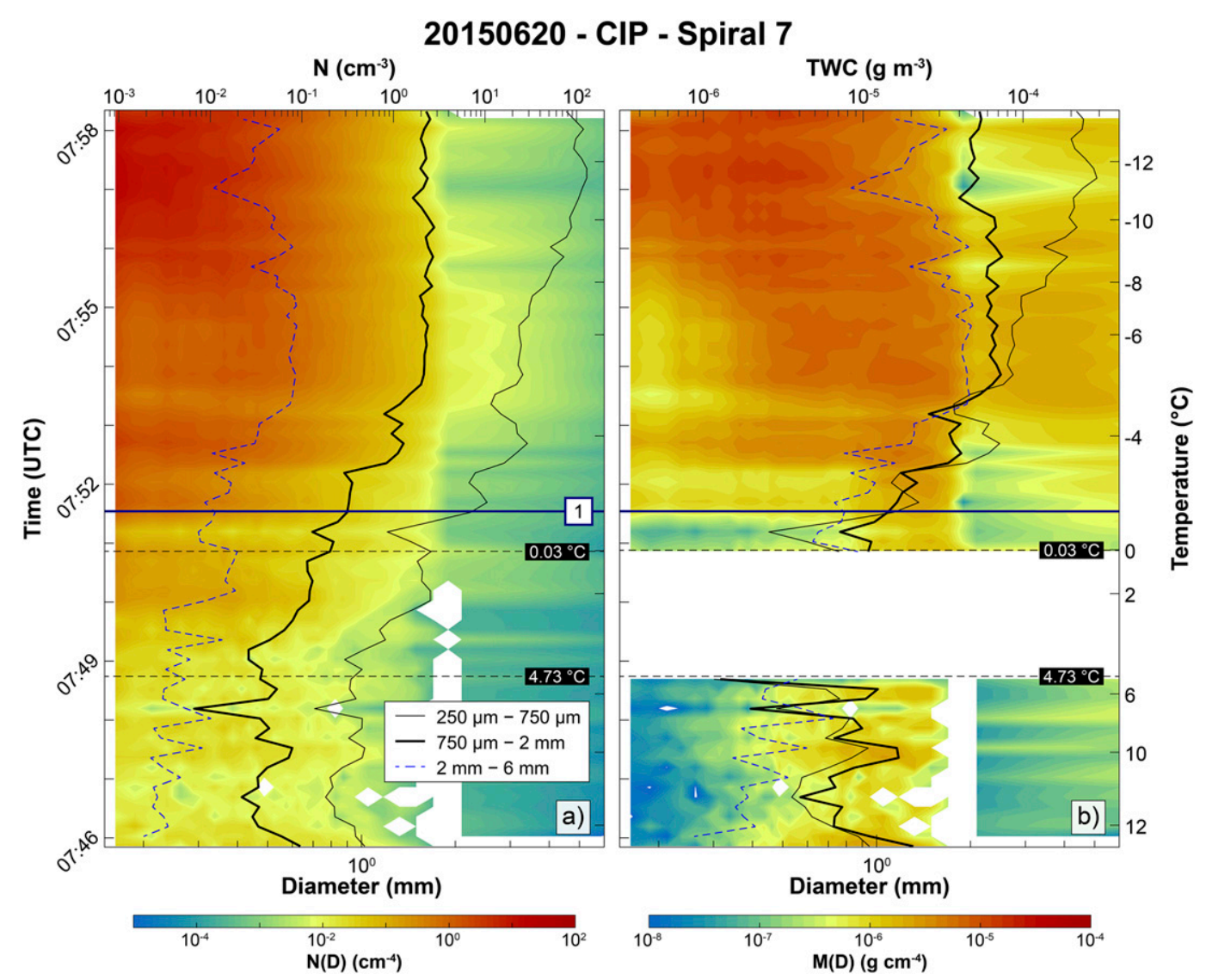

FIG. 21. As in Fig. 8, but for S7. The dark blue horizontal line labeled as "1" in each panel refers to the top of the subsaturated layer.

occurred from the evaporation of effectively lower concentrations of rain drops.

3) Mesoscale descent associated with the descending RIJ at the times of each of the RIJ spirals likely acted to continually suppress RH and allowed for ice to be present to much warmer $T$ than expected absent any external forcing. The latent cooling associated with sublimation, melting, and evaporation within the persistent layers of subsaturation above, within, and below the ML of the 20 June MCS over the course of at least $3 \mathrm{~h}$ is inferred to have contributed to the downward forcing of the RIJ.

The analyses of this unprecedented dataset allowed for the formulation of the conceptual cross sections in Fig. 22, which detail some of the key characteristics and inferred processes within the 20 June MCS. Regardless of whether the RIJ is present (Fig. 22a) or not (Fig. 22c), ice particles descending above the ML in the ESR grow primarily by aggregation, with individual particle mass and dimension increasing at the expense of total particle number. As these particles approach the ML, they enter an ice-subsaturated layer where sublimation commences, preferentially removing small particles from the population, limiting growth by aggregation, while cooling and moistening the environment. At least in the vicinity of the RIJ, these effects wane as the environment moistens downward in time and toward the TZ, as seen between S4/S5 and S7 (Fig. 22a). Particle concentrations in the TZ are notably lower than observed in the ESR, in part due to less precipitation there as hydrometeors are ejected rearward over the $\mathrm{TZ}$ from the convective line and fall within the ESR (Figs. 22a,b). As in the ESR, aggregation is common in the TZ, though with far subtler evidence of melting onset at $0^{\circ} \mathrm{C}$.

Enhanced cooling by sublimation and evaporation within the TZ ML limits melting, with most particles completely sublimating/evaporating prior to melting completion. The latent cooling imparted by sublimation, melting, and evaporation all contribute to the generation of downdraft circulations capable of forcing the descent of the RIJ. This mesoscale descent accelerates ice to warmer $T$ prior to melting completion and/or complete sublimation/evaporation, with 


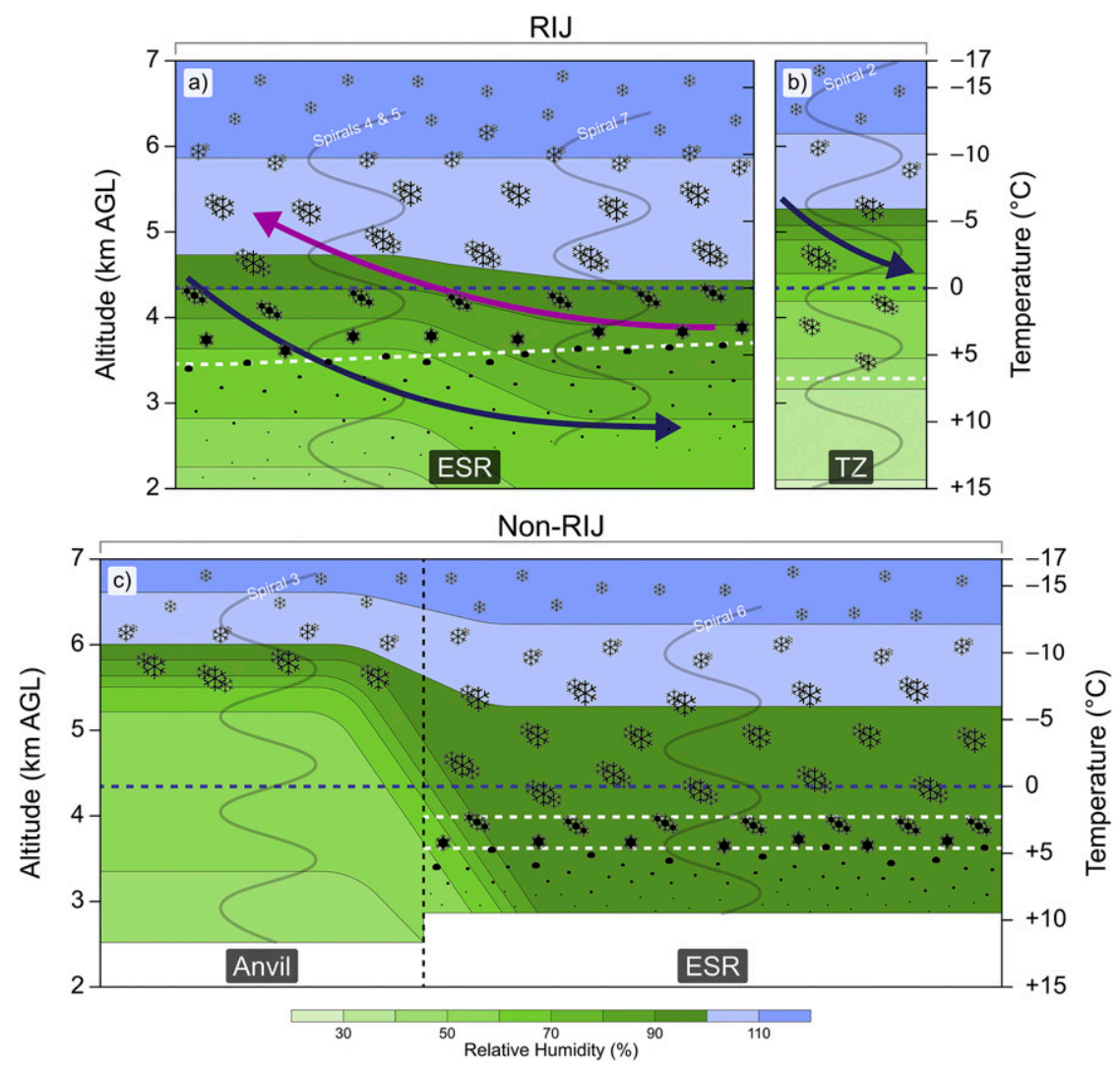

FIG. 22. Conceptual schematics detailing the environment and inferred microphysical processes within the 20 Jun 2015 MCS as functions of both altitude (km AGL) and temperature $\left({ }^{\circ} \mathrm{C}\right)$ in the vicinity of the RIJ within the ESR [(a); region given by the solid red box in Fig. 1] and TZ [(b); region given by the dashed light blue box in Fig. 1], and in regions removed from the RIJ influence [(c); region given by the dashed dark blue box in Fig. 1]. Filled contours represent $\mathrm{RH}$ (with respect to liquid water for $T>0^{\circ} \mathrm{C}$, and with respect to ice for $T \leq 0^{\circ} \mathrm{C}$ ). The dashed blue line represents the $0^{\circ} \mathrm{C}$ isotherm, while dashed white lines represent the ML boundaries [where the top of the ML in (a) and (b) is coincident with the $0^{\circ} \mathrm{C}$ isotherm]. The vertical black dashed line in (b) denotes the boundary between the anvil region and the ESR. The general location and vertical extent of relevant spiral profiles are given by curved gray lines. The main axis of the RIJ is given by the dark blue arrow in (a) and (b), and location of FTR flow given by the dark magenta arrow in (a). The inferred processes of aggregation, sublimation, melting, and evaporation are illustrated by ice crystal and rain drop icons.

adiabatic warming acting to counter any moistening imparted by sublimation and evaporation.

Removed from the RIJ (Fig. 22c), melting onset is delayed to $T>0^{\circ} \mathrm{C}$, with completion observed over a shallower layer than observed near the RIJ. Apart from the absence of the RIJ, the delay in melting onset is not readily attributable to specific MCS regions, or degree of ambient subsaturation; any such relationships may have been obscured by the sampling of different particle populations through the column. In the absence of the mesoscale descent and adiabatic warming associated with the RIJ, particle sublimation and evaporation readily moisten the non-RIJ ESR environment, approaching saturation through much of the observed area. The non-RIJ anvil region exhibited a sharp gradient in RH well above the $0^{\circ} \mathrm{C}$ isotherm, coupled with complete sublimation of ice particles there, or at least reduction of concentrations to below those detectable by the CIP.

The observations of the 20 June 2015 PECAN MCS presented in this study offers an unprecedented look at how the microphysical and thermodynamic characteristics vary relative to the regions within, and time evolution of a single severe MCS. A more comprehensive companion study will consider observations from 15 MCSs, including all 37 spiral profiles executed during PECAN and the 16 spiral profiles from BAMEX, to provide an aggregate statistical analysis of how thermodynamic 
and microphysical characteristics vary among the three main MCS regions (the TZ, ESR, and anvil region).

Acknowledgments. This study was funded by the National Science Foundation under Grants AGS1359098, AGS 1842094, AGS-1841966, and AGS1701225, with additional support provided by the NSSL Director's Discretionary Research Fund. We would like to thank the NOAA P-3 flight crew for acquiring the PECAN dataset. Conrad Ziegler and David Jorgensen of the National Severe Storms Laboratory (NSSL) are acknowledged for their efforts in obtaining flight hour support for the P-3 service during PECAN. We also acknowledge the work of Brittany Welsh and Troy Zaremba who manually identified the majority of the representative particle images for the PECAN spirals. Finally, Annette Foerster is acknowledged for creating the aircraft motion correction files for the PECAN NOAA Tail Doppler Radar data. Some of the computing for this project was performed at the OU Supercomputing Center for Education \& Research (OSCER) at the University of Oklahoma (OU).

\section{APPENDIX A}

\section{Extension of Size Distributions beyond the CIP Range}

To characterize the distribution of particle number and mass within and beyond the size range normally observed by the PIP, bulk TWC observations from the SEA WCM-2000 probe were used in mass closure tests to determine the most likely $N(D)$ in the size range beyond which the $N(D)$ were sampled by the CIP. Although there is considerable uncertainty in this extension, this approach is better than assuming $N(D)=0$ for such large particle sizes because a bulk measurement is available and is consistent with approaches used in past studies (e.g., M07).

The TWC of particles within the CIP size range (TWC $\mathrm{TIP}_{\mathrm{CI}}$ ) was estimated from the habit-dependent $m-D$ relations, which when subtracted from the SEA

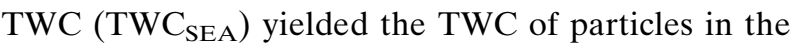
extended size range $\left(\mathrm{TWC}_{\mathrm{ext}}\right)$. Following $\mathrm{McF}$ arquhar et al. (2007b), an exponential form of $N(D)$ was assumed in the extended size range. Another constraint is given by the continuity of the extended distribution and that observed at the largest CIP maximum dimension $\left(D_{\max }\right)$, expressed by

$$
N\left(D_{\max }\right)=N_{0} e^{-\lambda D_{\max }},
$$

where $N_{0}$ is the intercept, and $\lambda$ is the slope. Thus, by closure for each 10 -s averaged PSD the $\mathrm{TWC}_{\mathrm{ext}}$ is expressed by

$$
\mathrm{TWC}_{\mathrm{ext}}=\int_{D_{\max }}^{\infty} N_{0} e^{-\lambda D} a D^{b} d D,
$$

where $a\left(0.00825 \mathrm{~g} \mathrm{~cm}^{-b}\right)$ and $b(2.4806)$ represent $m-D$ coefficients appropriate for a trailing stratiform region behind a convective line, as derived by Finlon et al. (2019) using observations from a flight leg within the ESR on 20 May 2011 MCS during MC3E.

The PSD extension was used only for times when $\mathrm{TWC}_{\text {ext }}$ (equal to $\mathrm{TWC}_{\mathrm{SEA}}-\mathrm{TWC}_{\mathrm{CIP}}$ ) was greater than $0.005 \mathrm{~g} \mathrm{~m}^{-3}$, the approximate sensitivity of the SEA probe. A total of 42 CIP PSDs ( $~ 8 \%$ of the 491 observed 10 -s PSDs) had a $\mathrm{TWC}_{\mathrm{ext}}$ less than this value, suggesting that little to no mass was associated with large particles beyond the CIP size range at those times. The CIP observations alone were expected to adequately represent the particle size distributions in those instances and were retained, with null values for $N(D)$ in the extended size range. The alternative, discarding these PSDs, would have biased the data away from those periods with few or no large particles. In addition, 53 CIP PSDs $(\sim 11 \%)$ were retained and not extended when fewer than 10 of the 34 CIP size bins contained nonzero values, as solutions for $N_{0}$ and $\lambda$ were often poorly constrained for those distributions. Finally, an additional six CIP PSDs $(\sim 1 \%)$ were not extended as solutions for $N_{0}$ and $\lambda$ were not possible.

Using $N_{0}$ and $\lambda$ derived for each 10-s averaged PSD, the observed $N(D)$ was extended to $D=12 \mathrm{~mm}$, with $M(D)$ calculated using the Finlon et al. (2019) $m-D$ relationship, and additional bulk quantities such as $N_{t}$ and $D_{\mathrm{mm}}$ calculated over the interval $0.125 \leq D \leq 12 \mathrm{~mm}$. The mass distribution function $M(D)$ peaked at $D>$ $2 \mathrm{~mm}$ in 69 CIP PSDs $(\sim 14 \%)$, in which cases more than half of the mass was assumed to be contained in particle sizes larger than those observed. While it is unknown how well the extended PSDs characterize $N(D)$ for these larger particles since no direct observations are available, the fits are an acceptable alternative to ignoring time periods with large mass contributions from particles with $D>2 \mathrm{~mm}$.

\section{APPENDIX B}

\section{List of Acronyms and Abbreviations}

2DC

2DP
Two-dimensional Cloud Probe

Two-dimensional Precipitation Probe 
$\mathcal{A}$

$a / b$

B1

BAMEX

CIP

$D$

$D_{\max }$

$D_{\mathrm{mm}}$

ESR

FTR

G09

KABR

KFSD

KUDX

$m-D$

$M(D)$

M07

MC3E

MCS

ML

$N(D)$

$N_{0}$

NOAA

$N_{t}$

OAP

PECAN

PIP

PRE-

STORM

PRF

PSD

RH

RIJ

RTF

S09

S1-7

SAMURAI Spline Analysis at Mesoscale Utilizing Aircraft and Radar Instrumentation

SEA WCM- Science Engineering Associates Inc. 2000

Area ratio (projected area of a particle divided by the area of a circle with diameter $D$ )

Coefficients used in mass-diameter relationships

First spiral profile executed within the 29 June 2003 BAMEX MCS

Bow Echo and Mesoscale Convective Vortex Experiment

Cloud Imaging Probe

Maximum particle dimension (diameter of smallest enclosing circle)

Maximum particle diameter observed in a given CIP PSD

Median mass diameter

Enhanced stratiform region

Front-to-rear [flow]

Grim et al. (2009)

Aberdeen, South Dakota, WSR-88D radar

Sioux Falls, South Dakota, WSR-88D radar

Rapid City, South Dakota, WSR-88D radar

Mass-diameter relationship

Particle mass distribution function

McFarquhar et al. (2007a)

Midlatitude Continental Convective Clouds Experiment

Mesoscale convective system

Melting layer

Particle number distribution function

Intercept term of the exponential form of the number distribution function

National Oceanic and Atmospheric Administration

Total particle number concentration

Optical array probe

Plains Elevated Convection at Night Experiment

Precipitation Imaging Probe

Preliminary Regional Experiment for STORM-Central

Pulse repetition frequency

Particle size distribution

Relative humidity (w.r.t. liquid water for $T>0^{\circ} \mathrm{C}$, and w.r.t. ice for $T \leq 0^{\circ} \mathrm{C}$ )

Rear inflow jet

Rear-to-front [flow]

Smith et al. (2009)

Spiral profiles 1-7 executed on 20 June 2015 during PECAN

multielement water content system
SHSR

$T$

TDR

TWC

$\mathrm{TWC}_{\mathrm{CIP}}$

$\mathrm{TWC}_{\mathrm{ext}}$

TWC $_{\text {SEA }}$

TZ

WSR-88D

$\lambda$

REFERENCES

Alford, A. A., M. I. Biggerstaff, and G. D. Carrie, 2018: A method for correcting staggered pulse repetition time (PRT) and dual pulse repetition frequency (PRF) processor errors. Zenodo, accessed 7 July 2018, https://doi.org/10.5281/zenodo.1306295.

Baumgardner, D., and A. Korolev, 1997: Airspeed corrections for optical array probe sample volumes. J. Atmos. Oceanic Technol., 14, 1224-1229, https://doi.org/10.1175/1520-0426(1997) 014<1224:ACFOAP > 2.0.CO;2.

Bell, M. M., M. T. Montgomery, and K. A. Emanuel, 2012: Air-sea enthalpy and momentum exchange at major hurricane wind speeds observed during CBLAST. J. Atmos. Sci., 69, 3197-3222, https://doi.org/10.1175/JAS-D-11-0276.1.

_ - W.-C. Lee, C. A. Wolff, and H. Cai, 2013: A solo-based automated quality control algorithm for airborne tail Doppler radar data. J. Appl. Meteor. Climatol., 52, 2509-2528, https:// doi.org/10.1175/JAMC-D-12-0283.1.

_ J. Martinez, D. M. Stechman, R. M. Rauber, G. M. McFarquhar, and A. Marchi, 2018: Structure and dynamics of an intense rear-inflow jet observed on 20 June 2015 during PECAN. Special Symp. on Plains Elevated Convection At Night (PECAN), Austin, TX, Amer. Meteor. Soc., 3.7, https:// ams.confex.com/ams/98Annual/webprogram/Paper334395.html.

Biggerstaff, M. I., and R. A. Houze, 1991: Kinematic and precipitation structure of the 10-11 June 1985 squall line. Mon. Wea. Rev., 119, 3034-3065, https://doi.org/10.1175/1520-0493(1991) $119<3034:$ KAPSOT $>2.0 . \mathrm{CO} ; 2$.

— and - 1993: Kinematics and microphysics of the transition zone of the 10-11 June 1985 squall line. J. Atmos. Sci., 50, 3091-3110, https://doi.org/10.1175/1520-0469(1993)050<3091: KAMOTT $>2.0 . \mathrm{CO} ; 2$.

Braun, S. A., and R. A. Houze, 1994: The transition zone and secondary maximum of radar reflectivity behind a midlatitude squall line: Results retrieved from Doppler radar data. J. Atmos. Sci., 51, 2733-2755, https://doi.org/10.1175/15200469(1994)051<2733:TTZASM > 2.0.CO;2.

, and - 1997: The evolution of the 10-11 June 1985 PRESTORM squall line: Initiation, development of rear inflow, and dissipation. Mon. Wea. Rev., 125, 478-504, https://doi.org/ 10.1175/1520-0493(1997)125<0478:TEOTJP>2.0.CO;2. 
Brown, P. R. A., and P. N. Francis, 1995: Improved measurements of the ice water content in cirrus using a total-water probe. J. Atmos. Oceanic Technol., 12, 410-414, https://doi.org/ 10.1175/1520-0426(1995)012<0410:IMOTIW>2.0.CO;2.

Cai, H., W.-C. Lee, M. M. Bell, C. A. Wolff, X. Tang, and F. Roux, 2018: A generalized navigation correction method for airborne Doppler radar data. J. Atmos. OceanicTechnol., 35, 1999-2017, https://doi.org/10.1175/JTECH-D-18-0028.1.

Cunning, J. B., 1986: The Oklahoma-Kansas. Preliminary regional experiment for STORM-central. Bull. Amer. Meteor. Soc., 67, 1478-1486, https://doi.org/10.1175/1520-0477(1986)067<1478: TOKPRE $>2.0 . \mathrm{CO} ; 2$.

Davis, C. A., and Coauthors, 2004: The Bow Echo and MCV Experiment: Observations and opportunities. Bull. Amer. Meteor. Soc., 85, 1075-1094, https://doi.org/10.1175/BAMS85-8-1075.

Field, P. R., R. Wood, P. R. A. Brown, P. H. Kaye, E. Hirst, R. Greenaway, and J. A. Smith, 2003: Ice particle interarrival times measured with a fast FSSP. J. Atmos. Oceanic Technol., 20, 249-261, https://doi.org/10.1175/1520-0426(2003) $020<0249$ :IPITMW $>2.0$. CO 2 .

— A. J. Heymsfield, and A. Bansemer, 2006: Shattering and particle interarrival times measured by optical array probes in ice clouds. J. Atmos. Oceanic Technol., 23, 1357-1371, https:// doi.org/10.1175/JTECH1922.1.

Finlon, J. A., G. M. McFarquhar, S. W. Nesbitt, R. M. Rauber, H. Morrison, W. Wu, and P. Zhang, 2019: A novel approach for characterizing the variability in mass-dimension relationships: Results from MC3E. Atmos. Chem. Phys., 19, 3621-3643, https://doi.org/10.5194/acp-19-3621-2019.

Gallus, W. A., 1996: The influence of microphysics in the formation of intense wake lows: A numerical modeling study. Mon. Wea. Rev., 124, 2267-2281, https://doi.org/10.1175/1520-0493(1996) 124<2267:TIOMIT>2.0.CO;2.

_ and R. H. Johnson, 1995: The dynamics of circulations within the trailing stratiform regions of squall lines. Part II: Influence of the convective line and ambient environment. J. Atmos. Sci., 52, 2188-2211, https://doi.org/10.1175/1520-0469(1995) 052<2188:TDOCWT>2.0.CO;2.

Geerts, B., and Coauthors, 2017: The 2015 Plains Elevated Convection At Night field project. Bull. Amer. Meteor. Soc. 98, 767-786, https://doi.org/10.1175/BAMS-D-15-00257.1.

Grim, J. A., G. M. McFarquhar, R. M. Rauber, A. M. Smith, and B. F. Jewett, 2009: Microphysical and thermodynamic structure and evolution of the trailing stratiform regions of mesoscale convective systems during BAMEX. Part II: Column model simulations. Mon. Wea. Rev., 137, 1186-1205, https:// doi.org/10.1175/2008MWR2505.1.

$\mathrm{Gu}, \mathrm{Y}$., and K. N. Liou, 2000: Interactions of radiation, microphysics, and turbulence in the evolution of cirrus clouds. J. Atmos. Sci., 57, 2463-2479, https://doi.org/10.1175/15200469(2000)057\%3C2463:IORMAT\%3E2.0.CO;2.

Helmus, J. J., and S. M. Collis, 2016: The Python ARM Radar Toolkit (Py-ART), a library for working with weather radar data in the Python programming language. J. Open Res. Software, 4, e25, https://doi.org/10.5334/jors.119.

Heymsfield, A. J., A. Bansemer, M. R. Poellot, and N. Wood, 2015: Observations of ice microphysics through the melting layer. J. Atmos. Sci., 72, 2902-2928, https://doi.org/10.1175/ JAS-D-14-0363.1.

Hogan, R. J., L. Tian, P. R. A. Brown, C. D. Westbrook, A. J. Heymsfield, and J. D. Eastment, 2012: Radar scattering from ice aggregates using the horizontally aligned oblate spheroid approximation. J. Appl. Meteor. Climatol., 51, 655-671, https:// doi.org/10.1175/JAMC-D-11-074.1.

Holroyd, E. W., 1987: Some techniques and uses of 2D-C habit classification software for snow particles. J. Atmos. Oceanic Technol., 4, 498-511, https://doi.org/10.1175/1520-0426(1987) 004\%3C0498:STAUOC\%3E2.0.CO;2.

Houze, R. A., M. I. Biggerstaff, S. A. Rutledge, and B. F. Smull, 1989: Interpretation of Doppler weather radar displays of midlatitude mesoscale convective systems. Bull. Amer. Meteor. Soc., 70, 608-619, https://doi.org/10.1175/15200477(1989)070<0608:IODWRD > 2.0.CO;2.

Jackson, R. C., and Coauthors, 2012: The dependence of ice microphysics on aerosol concentration in arctic mixed-phase stratus clouds during ISDAC and M-PACE. J. Geophys. Res., 117, D15207, https://doi.org/10.1029/2012JD017668.

, G. M. McFarquhar, J. L. Stith, M. Beals, R. A. Shaw, J. Jensen, J. Fugal, and A. Korolev, 2014: An assessment of the impact of antishattering tips and artifact removal techniques on cloud ice size distributions measured by the $2 \mathrm{D}$ cloud probe. J. Atmos. Oceanic Technol., 31, 2567-2590, https:// doi.org/10.1175/JTECH-D-13-00239.1.

Jensen, E., D. Starr, and O. B. Toon, 2004: Mission investigates tropical cirrus clouds. Eos, Trans. Amer. Geophys. Union, 85, 45-50, https://doi.org/10.1029/2004EO050002.

Jensen, M. P., and Coauthors, 2016: The Midlatitude Continental Convective Clouds Experiment (MC3E). Bull. Amer. Meteor. Soc., 97, 1667-1686, https://doi.org/10.1175/BAMS-D-14-00228.1.

Joe, P., and P. T. May, 2003: Correction of dual PRF velocity errors for operational Doppler weather radars. J. Atmos. Oceanic Technol., 20, 429-442, https://doi.org/10.1175/1520-0426(2003) 20<429:CODPVE $>2.0 . \mathrm{CO} ; 2$.

Jorgensen, D. P., T. J. Matejka, and J. D. DuGranrut, 1996: Multibeam techniques for deriving wind fields from airborne Doppler radars. Meteor. Atmos. Phys., 59, 83-104, https:// doi.org/10.1007/BF01032002.

, T. R. Shepherd, and A. S. Goldstein, 2000: A dual-pulse repetition frequency scheme for mitigating velocity ambiguities of the NOAA P-3 airborne Doppler radar. J. Atmos. Oceanic Technol., 17, 585-594, https://doi.org/10.1175/15200426(2000)017<0585:ADPRFS $>2.0$. CO;2.

Korolev, A., and G. A. Isaac, 2005: Shattering during sampling by OAPs and HVPS. Part I: Snow particles. J. Atmos. Oceanic Technol., 22, 528-542, https://doi.org/10.1175/ JTECH1720.1.

, E. Emery, J. W. Strapp, S. Cober, G. A. Isaac, M. Wasey, and D. Marcotte, 2011: Small ice particles in tropospheric clouds: Fact or artifact? Airborne icing instrumentation evaluation experiment. Bull. Amer. Meteor. Soc., 92, 967-973, https:// doi.org/10.1175/2010BAMS3141.1.

Lo, K. K., and R. E. Passarelli, 1982: The growth of snow in winter storms: An airborne observational study. J. Atmos. Sci., 39, 697-706, https://doi.org/10.1175/1520-0469(1982)039<0697: TGOSIW >2.0.CO;2.

Lowe, P. R., and J. M. Ficke, 1974: The computation of saturation vapor pressure. Naval Environmental Prediction Research Facility, Monterey, CA, 28 pp.

Marinescu, P. J., S. C. van den Heever, S. M. Saleeby, and S. M. Kreidenweis, 2016: The microphysical contributions to and evolution of latent heating profiles in two MC3E MCSs. J. Geophys. Res. Atmos., 121, 7913-7935, https://doi.org/ 10.1002/2016JD024762.

McFarquhar, G. M., and A. J. Heymsfield, 1996: Microphysical characteristics of three anvils sampled during the central equatorial 
Pacific experiment. J. Atmos. Sci., 53, 2401-2423, https://doi.org/ 10.1175/1520-0469(1996)053<2401:MCOTAS >2.0.CO;2.

- M. S. Timlin, R. M. Rauber, B. F. Jewett, J. A. Grim, and D. P. Jorgensen, 2007a: Vertical variability of cloud hydrometeors in the stratiform region of mesoscale convective systems and bow echoes. Mon. Wea. Rev., 135, 3405-3428, https:// doi.org/10.1175/MWR3444.1.

, G. Zhang, M. R. Poellot, G. L. Kok, R. McCoy, T. Tooman, A. Fridlind, and A. J. Heymsfield, 2007b: Ice properties of single-layer stratocumulus during the mixed-phase Arctic cloud experiment: 1. Observations. J. Geophys. Res., 112, D24201, https://doi.org/10.1029/2007JD008633.

—_, and Coauthors, 2011: Indirect and semi-direct aerosol campaign: The impact of arctic aerosols on clouds. Bull. Amer. Meteor. Soc., 92, 183-201, https://doi.org/10.1175/ 2010BAMS2935.1.

-, and Coauthors, 2017: Processing of ice cloud in situ data collected by bulk water, scattering, and imaging probes: Fundamentals, uncertainties, and efforts toward consistency. Ice Formation and Evolution in Clouds and Precipitation: Measurement and Modeling Challenges, Meteor. Monogr., No. 58, Amer. Meteor. Soc., 11.1-11.33, https://doi.org/10.1175/ AMSMONOGRAPHS-D-16-0007.1.

—, J. A. Finlon, D. M. Stechman, W. Wu, R. C. Jackson, and M. Freer, 2018: University of Illinois/Oklahoma Optical Array Probe (OAP) processing software. Zenodo, accessed 5 July 2018, https://doi.org/10.5281/zenodo.1285969.

Oye, R., C. Mueller, and S. Smith, 1995: Software for radar translation, visualization, editing, and interpolation. Preprints, 27th Conf. on Radar Meteorology, Vail, CO, Amer. Meteor. Soc., 359-361.

Pandya, R. E., and D. R. Durran, 1996: The influence of convectively generated thermal forcing on the mesoscale circulation around squall lines. J. Atmos. Sci., 53, 2924-2951, https://doi.org/ 10.1175/1520-0469(1996)053<2924:TIOCGT>2.0.CO;2.

,-- , and M. L. Weisman, 2000: The influence of convective thermal forcing on the three-dimensional circulation around squall lines. J. Atmos. Sci., 57, 29-45, https://doi.org/10.1175/ 1520-0469(2000)057<0029:TIOCTF $>2.0 . C O ; 2$.

Purser, R. J., W.-S. Wu, D. F. Parrish, and N. M. Roberts, 2003: Numerical aspects of the application of recursive filters to variational statistical analysis. Part I: Spatially homogeneous and isotropic Gaussian covariances. Mon. Wea. Rev., 131, 1524-1535, https://doi.org/10.1175//1520-0493(2003)131<1524: NAOTAO $>2.0 . \mathrm{CO} ; 2$.
Rasmussen, R., and H. R. Pruppacher, 1982: A wind tunnel and theoretical study of the melting behavior of atmospheric ice particles. I: A wind tunnel study of frozen drops of radius $<500 \mu \mathrm{m}$. J. Atmos. Sci., 39, 152-158, https://doi.org/ 10.1175/1520-0469(1982)039<0152:AWTATS>2.0.CO;2.

Smith, A. M., G. M. McFarquhar, R. M. Rauber, J. A. Grim, M. S. Timlin, B. F. Jewett, and D. P. Jorgensen, 2009: Microphysical and thermodynamic structure and evolution of the trailing stratiform regions of mesoscale convective systems during BAMEX. Part I: Observations. Mon. Wea. Rev., 137, 1165-1185, https:// doi.org/10.1175/2008MWR2504.1.

Strapp, J. W., J. D. MacLeod, and L. E. Lilie, 2008: Calibration of ice water content in a wind tunnel/engine test cell facility. 15th Int. Conf. on Clouds and Precipitation, Cancun, Mexico, International Commission on Clouds and Precipation, 13.1, http://www.iccp-iamas.org/.

Willis, P. T., and A. J. Heymsfield, 1989: Structure of the melting layer in mesoscale convective system stratiform precipitation. J. Atmos. Sci., 46, 2008-2025, https://doi.org/10.1175/15200469(1989)046<2008:SOTMLI $>2.0$.CO;2.

Wu, W., and G. M. McFarquhar, 2016: On the impacts of different definitions of maximum dimension for nonspherical particles recorded by 2D imaging probes. J. Atmos. Oceanic Technol., 33, 1057-1072, https://doi.org/10.1175/JTECH-D-15-0177.1.

Yang, M.-J., and R. A. Houze, 1995: Sensitivity of squall-line rear inflow to ice microphysics and environmental humidity. Mon. Wea. Rev., 123, 3175-3193, https://doi.org/10.1175/ 1520-0493(1995)123<3175:SOSLRI > 2.0.CO;2.

Yuter, S. E., R. A. Houze, E. A. Smith, T. T. Wilheit, and E. Zipser, 2005: Physical characterization of tropical oceanic convection observed in KWAJEX. J. Appl. Meteor., 44, 385-415, https:// doi.org/10.1175/JAM2206.1.

Zhang, D.-L., and K. Gao, 1989: Numerical simulation of an intense squall line during 10-11 June 1985 PRE-STORM. Part II: Rear inflow, surface pressure perturbations and stratiform precipitation. Mon. Wea. Rev., 117, 2067-2094, https://doi.org/ 10.1175/1520-0493(1989)117<2067:NSOAIS >2.0.CO;2.

Zhang, J., and Coauthors, 2016: Multi-Radar Multi-Sensor (MRMS) quantitative precipitation estimation: Initial operating capabilities. Bull. Amer. Meteor. Soc., 97, 621-638, https://doi.org/10.1175/BAMS-D-14-00174.1.

Zipser, E. J., R. J. Meitín, and M. A. LeMone, 1981: Mesoscale motion fields associated with a slowly moving GATE convective band. J. Atmos. Sci., 38, 1725-1750, https://doi.org/ 10.1175/1520-0469(1981)038<1725:MMFAWA > 2.0.CO;2. 